NBER WORKING PAPER SERIES

\title{
THE LOCAL RESIDENTIAL LAND USE REGULATORY ENVIRONMENT \\ ACROSS U.S. HOUSING MARKETS: \\ EVIDENCE FROM A NEW WHARTON INDEX
}

\author{
Joseph Gyourko \\ Jonathan Hartley \\ Jacob Krimmel \\ Working Paper 26573 \\ http://www.nber.org/papers/w26573 \\ NATIONAL BUREAU OF ECONOMIC RESEARCH \\ 1050 Massachusetts Avenue \\ Cambridge, MA 02138 \\ December 2019
}

We appreciate the excellent work of Laura Gooderis and her colleagues at the International City Managers Association (ICMA) for helping implement the new survey used in this paper. Ingrid Ellen and participants in presentations at the 2019 NBER Summer Institute and at the Wharton School's Urban Lunch group provided valuable comments on an initial draft of this paper. We also benefited from the superb research assistance of Diane Ding, Anna Gao, Xinyu Ma and Sean McCulloch. Finally, we appreciate the financial support of the Research Sponsors Program of the Zell/Lurie Real Estate Center at Wharton. The views expressed herein are those of the authors and do not necessarily reflect the views of the National Bureau of Economic Research.

NBER working papers are circulated for discussion and comment purposes. They have not been peer-reviewed or been subject to the review by the NBER Board of Directors that accompanies official NBER publications.

(C) 2019 by Joseph Gyourko, Jonathan Hartley, and Jacob Krimmel. All rights reserved. Short sections of text, not to exceed two paragraphs, may be quoted without explicit permission provided that full credit, including $\odot$ notice, is given to the source. 
The Local Residential Land Use Regulatory Environment Across U.S. Housing Markets:

Evidence from a New Wharton Index

Joseph Gyourko, Jonathan Hartley, and Jacob Krimmel

NBER Working Paper No. 26573

December 2019

JEL No. R1,R14,R31,R52

\title{
ABSTRACT
}

We report results from a new survey of local residential land use regulatory regimes for over 2,450 primarily suburban communities across the U.S. The most highly regulated markets are on the two coasts, with the San Francisco and New York City metropolitan areas being the most highly regulated according to our metric. Comparing our new data to that from a previous survey finds that the housing bust associated with the Great Recession did not lead any major market that previously was highly regulated to reverse course and deregulate to any significant extent. Moreover, regulation in most large coastal markets increased over time.

\author{
Joseph Gyourko \\ University of Pennsylvania \\ The Wharton School of Business \\ 3620 Locust Walk \\ 1480 Steinberg-Dietrich Hall \\ Philadelphia, PA 19104-6302 \\ and NBER \\ gyourko@wharton.upenn.edu \\ Jonathan Hartley \\ Harvard Kennedy School \\ 79 John F. Kennedy Street \\ Cambridge, MA 02138 \\ jhartley@hks.harvard.edu
}

\author{
Jacob Krimmel \\ University of Pennsylvania \\ jkrimmel@wharton.upenn.edu
}

An appendix is available at http://www.nber.org/data-appendix/w26573 


\section{Introduction}

High house prices, especially in America’s larger coastal markets, have spawned growing concerns about housing affordability for middle class, not just low income, households. The potential role of local residential land use restrictions in helping to generate such high prices is an issue of growing importance in the public and academic spheres. In the public arena, this led to a host of proposed policy responses, including a recent Presidential Executive Order establishing a White House Council on Eliminating Regulatory Barriers to Affordable Housing. ${ }^{1}$ Regionally, this has been a topic of public debate in California especially, with recent proposed legislation that would have restricted localities from stopping residential construction in certain circumstances. In addition, the rise of a Yes In My Back Yard (YIMBY) political movement is a relatively new development in various parts of the country ranging from California and Oregon to Minnesota. ${ }^{2}$ The academic literature on the topic also has grown substantially in recent years. ${ }^{3}$

There are many challenges to producing convincing analysis of the impact of the local regulatory environment, but such research always starts with how to measure restrictiveness. ${ }^{4}$ In

\footnotetext{
${ }^{1}$ See https://www.whitehouse.gov/presidential-actions/executive-order-establishing-white-house-councileliminating-regulatory-barriers-affordable-housing/ for the text of the order.

${ }^{2}$ Last year saw the writing of a California state bill (SB 827) that would have limited the ability of localities to stop denser developments involving multifamily-type construction. For one of many analyses of this effort, which did not pass or even make it out of committee, see the Vox article at https://www.vox.com/cities-andurbanism/2018/2/23/17011154/sb827-california-housing-crisis. See the July 5, 2017, article in The Atlantic for more on the new YIMBYism movement. Entitled "From 'Not in My Backyard' to 'Yes in My Backyard'”, it may be accessed at https://www.theatlantic.com/business/archive/2017/07/yimby-groups-pro-development/532437/. The Oregon state legislature recently passed a bill to effectively ban single-family zoning in Oregon neighborhoods. See: https://www.oregonlive.com/politics/2019/06/bill-to-eliminate-single-family-zoning-in-oregon-neighborhoodspasses-final-legislative-hurdle.html. In late 2018, the Minneapolis City Council voted to eliminate single-family zoning, and in its stead, permit up to three housing units on each site. On this, see https://nytimes.com/2018/12/13/us/minneapolis-single-family-zoning.html.

${ }^{3}$ For example, see Albouy and Ehrlich (2018), Emrath, (2016), Gedal and Ellen (2018), Jackson (2016, 2018), Lin and Wachter (2019), and Turner, et. al. (2014) for some recent efforts. Gyourko and Molloy (2015) provide the most recent scholarly literature review, with Glaeser \& Gyourko (2018) describing how a restrictive supply side of housing markets appears to be affecting home prices in coastal markets especially.

${ }^{4}$ Prior efforts to measure the degree of regulatory restriction include Linneman, et. al. (1990), Glickfield and Levine (1992), Pendall, Puentes and Martin (2006), Gyourko, Saiz and Summers (2008) and Glaeser and Ward (2009). For other recent efforts on measuring restrictiveness, see the Terner Center's California Land Use data (http://californialanduse.org/index.html) and Brueckner and Singh (2018).
} 
this paper, we report results from a new survey of the residential land use regulatory environment in more than 2,450 primarily suburban communities across a wide array of metropolitan areas throughout the country. We construct a measure of regulatory restrictiveness called the Wharton Residential Land Use Regulatory Index (WRLURI). To distinguish the new index from the first Wharton survey conducted over a decade ago, we refer to the new measure as WRLURI2018 and the previous index as WRLURI2006.

Our index methodology provides a convenient way to rank individual communities and markets in terms of their regulatory restrictiveness. The index is standardized so that it has a mean of zero and a standard deviation of 1 , where a higher value implies more regulation. However, it does not reveal what regulation actually exists in places with different index value ranks. To provide a translation from index value to actual regulatory environment, we group communities by where they rank in the overall distribution of WRLURI2018 values. For example, we consider those in the bottom quartile of the WRLURI2018 distribution to be lightly regulated. Being relatively lightly regulated by our metric does not imply that the jurisdiction is unregulated or characterized by a near absence of residential land use controls restricting supply. Among this subset of communities, two entities (usually a local planning commission and a local council) typically are required to approve any project that needs rezoning. Even for projects not requiring a variance to the zoning code, it is not uncommon for lightly-regulated communities to require the approval of two local entities in order for the development to proceed. Density restrictions also are omnipresent. Ninety-four percent of the communities in the bottom quartile of the WRLURI2018 distribution have some type of minimum lot size requirement in at least one of their neighborhoods, with the typical minimum being less than one-half acre. It also takes a meaningful amount of time to get a proposal through the approval process even in these 
relatively lightly-regulated communities. The average time span between submitting a project for approval and receiving a decision is 3.4 months, which amounts to 111 days assuming thirty days per month.

Highly-regulated places (which we define as those with index values in the top quartile of the WRLURI2018 distribution) tend to be more regulated on multiple dimensions. Thus, they are not at the top of the rankings because they are extremely restrictive in only one or two facets of regulation. These places tend to have at least three different entities that must approve (and, thus, can veto) a project. Density restrictions are more severe on average, as the modal community among this group reports a $2+$ acre minimum lot size restriction in at least one of its neighborhoods. In addition, there is a more intense level of involvement in the regulatory process reported on the part of public and local officials in the places we rate as the most highly regulated. These jurisdictions are also likely to have open space requirements and exaction fee programs imposed on builders. Project review delay times are more than double those found in the lightly-regulated areas. The average project review time is 8.4 months, or 252 days presuming 30-day months. There also is a thick upper tail, with some communities reporting 1824 month review times (which we confirmed are not data error from misreporting in the survey).

The average regulatory environment looks like the mean of the lightly- and highlyregulated ones. Hence, there is no place (on average) where residential development is simple and quick in the sense that projects are reviewed quickly by a single entity that has final approval rights. The local residential regulatory environment now is a complex one, even among the communities that are not relatively highly regulated by our measure.

For the 44 metropolitan areas (technically, core-based statistical areas or CBSAs) in which there were at least ten communities responding to our survey, we report market-wide 
regulatory index values, which are the simple means of the individual communities’

WRLURI2018 values. The San Francisco and New York City CBSAs are the most highly regulated markets in the country by this metric, with each having a WRLURI2018 value that is more than one standard deviation above the national average. In addition, there is a clear regional pattern to the CBSA-level results (see Figure 1 and Table 5 below). Nine of the top 10 markets in terms of measured regulatory strictness are situated along the northeast coast (from Boston down through Washington, D.C.) or the west coast of the country (Seattle, Portland (OR), San Francisco and Los Angeles). The most lightly regulated among the group of larger metropolitan areas tend to be declining markets in the so-called Rust Belt region (e.g., Cleveland, OH, Grand Rapids, MI, Cincinnati, OH, Detroit, MI, and St. Louis, MO). These markets tend to have WRLURI2018 values that are about one-quarter to one-third of a standard deviation below the national mean. ${ }^{5}$ The interquartile range of this group contains a wide array of markets across the rest of the country. Markets with WRLURI2018 index values within one-tenth of a standard deviation from zero include Houston, TX, Columbus, OH, San Antonio, TX, and Pittsburgh, PA. By definition, these markets have the average residential land use regulatory climate according to our measure.

The 2018 survey allows us to paint a broad picture of the current regulatory environment. However, the cross section cannot tell us how the regulatory environment changed over timeeither in aggregate or for certain markets or regions. To document changes, we exploit data from our 2006 Wharton survey (Gyourko, Saiz, Summers (2008)) and measure changes in responses across the two instruments. Depending upon the specific question, there typically are from 750900 communities that answered it in both surveys. The number that fully answered both surveys

\footnotetext{
${ }^{5}$ Given that the index is standardized with a mean of zero and standard deviation of 1, this implies that communities in many smaller markets make up the bulk of places with even lower WRLURI2018 index values.
} 
is just over 500. We believe this is the first consistent nationwide data to document changes in residential land use regulation at the local jurisdiction level.

Based on how the same community answered identical questions across both surveys, we reach the following conclusions about how the residential land use regulatory environment has and has not changed since the first Wharton survey:

(1) The fundamental nature of the local regulatory environment has not changed much. That is, there is no evidence that broad strategies for regulating the development process or specific tools have been abandoned by many or most communities; nor do we see evidence of radically new methods in use. What existed near the start of the century is still there in basic form.

(2) There is no evidence that the Great Recession and its concomitant housing bust led most (or even many) local communities to adopt a new perspective that fostered widespread declines in regulatory intensity. The intensity of involvement in the regulatory process by local officials and the broader community is down on average, but that change is modest, and it could be due to when the surveys were taken (i.e., the first one just before the peak of the biggest housing boom in the post-war era; the second over a decade later and well into the recovery following the global financial crisis). In any event, the Great Recession clearly did not lead to general declines in regulatory intensity. Of course, there are individual communities who lessened local regulation by abandoning certain policies or enforcing them more leniently. However, at the housing market or CBSA-based level, there are no cases in which a previously highly-regulated area reversed course and became lightly-regulated on average (in absolute or relative terms). In fact, the regulatory burden increased at 
least modestly in the big metropolitan areas on both coasts, and those areas already were relatively highly regulated according to the first Wharton survey.

(3) In terms of the regulatory process, the number of entities needed to approve projects requiring a zoning variance is increasing in the typical place. This makes the process more cumbersome and increases the potential for projects to be vetoed. Density controls are also used more widely and are more severe on average. The use of minimum lot sizes to control density is now almost omnipresent. And, it is no longer uncommon to see one acre (or greater) minimums in suburban areas; this was much rarer in the 2006 data. Other regulations investigated (e.g., open space requirements and affordable housing programs) do not show such big increases in aggregate, but there also is no evidence they are declining — either in usage or strictness of enforcement. The one exception involves impact fees on developers. The aggregate propensity for communities to impose them fell by one-third, from about $75 \%$ in the 2006 survey to $50 \%$ in 2018.

The plan of the paper is as follows. The next section describes how we construct the aggregate regulatory index for each place, building up from a dozen subindexes that measure different components of the local regulatory environment. Section III then reports results. This section describes the distribution across individual communities throughout the nation and then reports on market-level variation across space. We also translate what the index numbers mean in terms of actual regulation in place. Section IV describes how the regulatory environment has changed over time. Section V briefly summarizes and concludes. 


\section{Index Creation}

A key reason it is so difficult to accurately measure the restrictiveness of the local regulatory environment is because there are many different ways that regulation can affect supply. The most direct mechanism is via a hard cap on permitting or building of new housing units. However, communities also can influence supply in indirect ways by enacting policies that raise costs via delay in evaluating project proposals, imposing expensive design or density restrictions, etc. To help describe such a complex regulatory environment, our survey asks a series of questions focused on the process of local regulation, as well as a few specific ways in which builders are constrained by rule or law. As with the 2006 survey, the questions fall into one of three categories. The first asks about the general nature or characteristics of the regulatory process. These include specific queries about who is involved in the process (e.g., local council, state legislature, local citizens, etc.) and how important these actors are. The second set of questions asks about the overarching rules of the process by which the housing market is regulated. These queries identify whether there are any explicit caps on permitting or construction, as well as the nature of density restrictions such as minimum lot size regulations. The survey also includes inquiries about other rules such as affordable housing requirements, impact fees and exactions. This section also asks about the typical time lag between when a project is proposed by a builder and when the local government provides a response to the application. The third and final set of questions asks about outcomes, such as changes in the cost of lot development, as well as the number of re-zoning permits applied for by developers. The complete 2018 survey instrument is reproduced in Appendix 1; that for the 2006 survey follow in Appendix 2. 


\section{II.A. Subindex Creation}

Using individual community responses to each survey question, we create a dozen separate indexes that capture the different components of the local regulatory environment. Each subindex is described just below, with Appendix 3 providing a detailed mapping of each underlying question to the subindex in which it is used. These subindexes are then used to create our summary measure of regulatory stringency, the WRLURI2018 index.

\section{Local Political Pressure Index (LPPI)}

This subindex quantifies the degree to which various actors are involved in the local residential development process. The underlying data largely come from responses to Question 3 on our survey, which asks the following: "In your community, how involved are the following in affecting residential building activities and/or growth management procedures?” Respondents then rate the importance of various actors—-such as a local council or managers, local community pressure or other listed entity--on a 1 to 5 scale, with 1 indicating the actors have no involvement and 5 indicating they are "Very Involved." To these scores, we add the number of land preservation and conservation-related ballot initiatives approved by the municipality between 2008 and August 2018. The ballot initiatives measure is based on the Trust for Public Land Landvote database. ${ }^{6}$

Scores are summed as follows:

(1) LPPI = LocalCouncil + Community Pressure + Other + BallotInitiatives, so that the range of answers is from a low of three $(1+1+1+0$, if the community responded that no local council was involved in the process, community pressure was not relevant, that there was no other group we did not list in Question 3, and there were no relevant ballot

\footnotetext{
${ }^{6}$ To access the database, see: https://tpl.quickbase.com/db/bbqna2qct?a=dbpage\&pageID=8.
} 
initiatives over the past decade) to 15 plus the number of ballot initiatives $(5+5+5+$ \#BallotInitiatives).

Note that a high score for this subindex (or for the next two) does not necessarily indicate a desire for a more restrictive regulatory environment. It probably does reflect a relatively high level of existing restrictiveness, but a high degree of public and local official involvement could arise from a desire to lighten the regulatory burden, not only to make it more restrictive.

\section{State Political Involvement Index (SPII)}

The State Political Involvement Index (SPII) is based on the answer to a single question asking how involved is the state legislature in influencing residential building activities and/or growth management procedures. Thus,

(2) SPII = StateLeg.

Because this is a component of Question 3 described above with respect to the LPPI, its answers also range from 1 (no involvement) to 5 (very involved).

\section{Court Involvement Index (CII)}

This is the final index regarding the actors involved in the local residential land use process. The CII is the sum of the reported local and state courts' involvement in affecting residential building activities and/or growth management (the sums of questions 3d and 3e, respectively). That is,

(3) CII = LocalCourt + StateCourt.

The potential range of values is from 2-10, with a value of two indicating that both local and state courts are not at all involved in the regulatory process, and a score of ten indicating that they are heavily involved. As with the first two subindexes, a higher degree of court involvement does not necessarily imply they are trying to make the local regulatory environment 
more restrictive. Increased court involvement could arise from a desire to lighten the regulatory burden or re-zone municipalities for higher density. That said, Ganong and Shoag’s (2017) measure of land use regulations, which counted the number of land use legal cases by state, was strongly positively correlated with the WRLURI2006 index, so more court involvement well may be indicative of a more restrictive regulatory environment.

\section{Local Project Approval Index (LPAI)}

Question 4 of our survey asks for a different type of information on the process of regulatory control—namely, who must approve different types of projects before they can be built and whether approval requires a supermajority vote in favor. This subindex pertains to projects that do not require any variance to the current zoning code (i.e., they are 'by right' because they do not violate any current rule or law).

The question asks which of nine entities have to approve a project before any housing can be built. Eight specific entities listed include: the local planning commission; local zoning board; local council, managers, or commissioners; the county board of commissioners; the county zoning board; an environmental review board; a public health office; or a design review board; the ninth is 'Other' in case there is another group we did not list that is relevant. ${ }^{7}$ Thus,

(4) LPAI = LocalPlan + LocZone + LocCouncil + CountyComm + CountyZone + Environ + PubHealth + Design + Other.

Response values for each entity range from 0-2. A zero indicates the entity does not have to approve the project. A value of one indicates that the entity does have to approve, but may do so by a simple majority vote. A value of 2 indicates that the entity must not only formally approve the project, but must do so by a supermajority vote of its decision makers. Hence, the

\footnotetext{
7 There were other relevant entities. For example, the California Coastal Commission often was listed by communities in the major coastal metropolitan areas of that state.
} 
possible range of values for this index runs from 0 -18. A value of zero indicates that there is no entity required to approve a 'by right' project, while a value of 18 would indicate that each of the eight listed entities, plus another listed by the respondent, must approve with a supermajority in favor.

\section{Local Zoning Approval Index (LZAI)}

The LZAI is created exactly as described above for the LPAI, except it pertains specifically to projects that do require some type of variance or change to the local zoning code (see the second half of Question 4 from the survey). Thus,

(5) LZAI = LocalPlan + LocZone + LocCouncil + CountyComm + CountyZone + Environ + PubHealth + Design + Other,

with the range of possible outcomes the same as for the LPAI subindex.

\section{Local Assembly Index (LAI)}

The LAI uses the final piece of data generated from Question 4. That question also asks whether a town meeting is required to approve any type of proposed residential project. Rather than include this information as a component of the LPAI and LZAI indexes just described, we use it to create a separate index to capture whether the local regulatory environment requires some type of direct democracy involvement of the local population. Thus,

(6) $L A I=$ TownMeet, with the index values ranging from $0-2 .^{8}$

\section{Supply Restrictions Index (SRI)}

\footnotetext{
${ }^{8}$ We do not sum across the types of projects in the creation of this index. If any type of project approval requires some type of town meeting, the subindex takes on a value of 1 or 2 (if supermajority approval is required), and a value of 0 if no town meeting is required.
} 
The Supply Restrictions Index reflects the extent to which there are explicit annual caps on the supply of new housing. Question 8 of the survey asks whether (in a simple 'yes or no' sense) the respondent community places annual limits on the total allowable number of permitted units, total number units constructed, units per dwelling or the aggregate number of buildings constructed. More specifically, the question asks whether there are limits for the following: building permits for single family homes or multifamily units; the number of single family homes or multifamily units authorized for construction; the number of multifamily units buildings authorized for construction; and the number of units in multifamily dwellings. The SRI is the simple sum of the number of limits on building permits, construction, or number of dwellings and units and is constructed as follows:

(7) SRI = SFPermits + MFPermits + SFConst + MFConst + MFBuild + MFUnitsDwell . Hence, its value ranges from a low of zero to a high of six.

\section{Density Restriction Index (DRI)}

One way to constrain housing supply is to impose density restrictions. Question 7 of the survey asks whether the community has any minimum lot size requirement at all, and if so, the size of the largest minimum required in any neighborhood within the jurisdiction. Specifically, respondents were asked to indicate whether their largest minimum required that homes be built on less than one-half acre of land, from 0.5-1.0 acres, from 1-2 acres or from 2+ acres.

The DRI subindex takes on values ranging from 0-4 and is constructed as follows:

(8) $D R I=0$ if there is no minimum lot size regulation anywhere in the jurisdiction $=1$ if there is a minimum, but it is no larger than 0.5 acres

$=2$ if there is a minimum, and the largest one is from 0.5-1.0 acres

$=3$ if there is a minimum, and the largest one is from 1.0-2.0 acres

$=4$, if there is a minimum, and the largest one is for more than 2 acres.

\section{Open Space Index (OSI)}


Question 9 of the survey asks about different types of regulations that communities might impose on developers in return for the right to build. One is whether residential real estate developers are required to provide some type of space for the community to use (or pay a fee in lieu of providing such space). This could reflect an explicit open space requirement or some mandate that space be provided for a specific community use. For simplicity, we call this the Open Space Index, with OSI measured as 0-1 dummy where a value of one indicates that some type of dedicated space is required to be provided (or a financially equivalent fee paid). Thus,

(9) OSI = 1 if some type of mandatory space provision is required; $=0$ otherwise.

\section{Exactions Index (EI)}

Question 9 also asked whether the community required developers to pay any type of impact fee or the allocable share of the costs of infrastructure. The EI also is a 0-1 variable and is measured as follows:

$$
E I=1 \text { if an impact fee exists and }=0 \text { otherwise. }
$$

\section{Affordable Housing Index (AHI)}

The final component to Question 9 asks whether developers were required to "Include affordable housing, however defined, in their projects” in order to be able to build in the jurisdiction. We interpret an answer in the affirmative to indicate that there exists some affordable housing requirement in the municipality. This also is a $0-1$ variable such that

$$
A H I=1 \text { an affordable housing program exists and }=0 \text { if not. }
$$

\section{Approval Delay Index (ADI)}

The final subindex used in creating our aggregate index is a measure of permit approval delay. The survey asks about project review time in several places (including questions 16, 17, 18, 20, and 22). The Approval Delay Index (ADI) combines the average review time for 
residential projects, rezoning requests involving multiple unit types and subdivision requests into a single metric. The ADI is calculated in several steps. First, we compute the simple averages of review time (reported in months) for:

(1) by-right single-family unit projects and by-right multifamily unit projects ((sfprojrev + mfprojrev)/2) from Questions 16a and 16b);

(2) not by-right single-family unit projects and not by-right multifamily unit projects ((nsfprojrev + nmfprojrev)/2) from Questions 17a and 17b);

(3) application for and issuance of a building permit for development of less than 50 single-family units, 50 or more single-family units, and multi-family units $((\operatorname{sfl} 50+\operatorname{sfm} 50+\mathrm{mf}) / 3)$ from Questions 20a, 20b, and 20c);

(4) application for subdivision approval and issuance of a building permit for development of less than 50 single-family units, 50 or more single-family units, and multi-family units ((subsfl50 + subsfm50 + submf)/3) from Questions 22a, 22b, and 22c).

We then take the average of these four numbers to arrive at the number of months involved in the Approval Delay Index (ADI). More specifically,

$$
\begin{aligned}
& \text { ADI }=\{((\text { sfprojrev }+ \text { mfprojrev }) / 2)+((\text { nsfprojrev }+ \text { nmfprojrev }) / 2)+ \\
& ((\text { sfl50 }+ \text { sfm50 }+ \text { mf }) / 3)+((\text { subsfl50 }+ \text { subsfm } 50+\text { submf }) / 3)\} / 4 .
\end{aligned}
$$

This average across such a wide range of potential projects is used because we believe it helps reduce potential measurement error in this variable.

\section{II.B. Creating the Aggregate Index (WRLURI2018)}


Factor analysis is used to create the Wharton Residential Land Use Regulatory Index. Specifically, we select the first factor from each subindex to create an aggregate WRLURI2018 value for each jurisdiction. ${ }^{9}$ As with the previous Wharton index, we employ this methodology to construct a single measure by which localities can be ranked based on the restrictiveness of their regulatory environments. We also standardize the WRLURI2018 measure such that the sample mean is 0 and its standard deviation is 1 , with lower (higher) values of the index reflecting a less (more) restrictive regulatory regime in the community.

Table 1 shows the weights, or factor loadings, of each subindex in the aggregate index, as well as the correlation with the aggregate index. ${ }^{10}$ Note that the Court Involvement Index, State Political Involvement Index, and Local Political Involvement Index have the highest factor loadings and almost the same strong correlation with the aggregate index, while the Density Restriction Index and Supply Restriction Index have the lowest factor loadings and weakest correlations with WRLURI18. This indicates that there is relatively high variation across communities in the different political and court involvement indexes, but not as much in the supply and density restriction measures. That implies the former set of subindexes are more influential in determining rankings of communities in terms of overall restrictiveness, but it does not mean they necessarily are the most influential in determining the absolute level of restrictiveness in a community.

\section{Results}

\section{III.A. Inside Versus Outside Metropolitan Areas}

\footnotetext{
${ }^{9}$ Stata's PCA routine is used to extract the principal component from each subindex.

${ }^{10}$ The factor loadings are the weights applied when multiplying by each of the subindexes (which are themselves standardized in the principal component analysis) to generate the WRLURI2018 index as a linear combination of the twelve subindexes.
} 
Our full sample contains complete subindex and aggregate index data on 2,472 communities across the nation. ${ }^{11}$ Information on the distribution of WRLURI2018 values for this sample are reported in the first column of Table 2. As noted above, the mean index value for the full sample is zero with a standard deviation of one by construction (see the first and second rows). ${ }^{12}$ More detail on the full distribution is provided in the remaining rows of the column. The interquartile range runs from -0.68 to 0.62 , so the middle fifty percent of communities have aggregate index values within seven-tenths of a standard deviation from the sample mean.

The second column reports index values for the 2,233 communities that lie within any core-based statistical area (CBSA) in the nation. Given that they represent 90 percent of the sample, their distribution looks much like that for the full sample. This is not the case for the 239 communities outside of CBSAs. Their mean WRLURI2018 value is 0.3 standard deviations below that for the metro area sample, and the median community outside a metropolitan area has an index value of -0.51 , which puts it one-half of a standard deviation below the full sample mean. While the average community outside of any CBSA is much less regulated by our measure, this does not hold for its entire distribution. The top tail of the non-CBSA sample-from the $90^{\text {th }}$ percentile and above--is nearly as highly regulated as the most regulated jurisdictions within metropolitan areas. That said, the remainder of this paper focuses on results for communities located within a CBSA.

\footnotetext{
${ }^{11}$ This includes cases in which we allocated answers. This was done for Questions 3,4,8 and 9 as follows. For example, Question 3 asks about the intensity of involvement in the regulatory process by six possible actors. If all subparts of the question were left blank, we left the responses as missing. However, if the locality indicated some type of involvement for one or more (but not all) of the actors, we used those responses and imputed a response of "No Involvement" (i.e., =1) for the other actors listed. Thus, we never impute any positive involvement and only impute no involvement when a question is at least partially answered. Allocation flags for these cases will be included in the publicly posted data so that researchers may see which observations were affected.

${ }^{12}$ All results in the main body of the paper are based on equal weighting of all relevant survey respondents. We investigated different weighting schemes that are discussed in Appendix 4. Weighting does not affect any major conclusion reported in the paper.
} 
III.B. What Does It Mean to be Lightly, Moderately and Highly Regulated in the U.S.?

Table 3 reports subindex and census information on communities within CBSAs. The first column reports this information for the 559 places in the bottom quartile of the WRLURI2018 distribution. These places have index values that are over -0.64 standard deviations below the global mean. For each subindex, the mean value across individual places in the bottom quartile is reported. Analogous information is then reported in the middle column of Table 3 for the 1,116 places with WRLURI2018 values within the interquartile range of that index. The third and final column reports information on the 558 places in the top quartile of the WRLURI2018 distribution.

Index values provide a convenient way to rank communities by their degree of regulatory restrictiveness, but they do not convey what it means to have a low, average or high degree of regulation in the country. Consequently, we describe in Table 4 what the underlying regulatory environment contains for communities with index values representative of those reported in the different columns of Table 3. For example, the first row in the middle column of Table 3 indicates that the average LPPI value for communities with WRLURI2018 values within the interquartile range of the distribution equals 8.61. As described above, that figure is the sum of responses to three questions that are themselves part of Question \#3 in the 2018 survey (plus a count of recent ballot initiatives). The top cell of the middle column of Table 4 then describes what those numbers mean in terms of the underlying political environment in which regulatory decisions are being made. A LPPI=8.61 is consistent with the underlying community having what it reported as high involvement from its local political officers (on a local council or commission), moderate involvement in terms of community pressure, little to no other type of 
local political involvement and no special ballot initiatives regarding the regulatory or growth management process.

A number of interesting results and patterns can be gleaned from Tables 3-4. First, being lightly-regulated (more formally, being in the bottom quartile of the WRLURI2018 CBSA-based distribution) does not mean these communities are unregulated or unrestricted. It is true that the underlying local and state political and legal environments are not ones in which there is intense involvement by politicians, judges or citizens. Thus, there is little evidence of pressure from the community to ratchet up regulation in these places. Not surprisingly, these places typically do not have public meeting requirement either. The LAI value of 0.33 indicates that only one-third of them do.

However, this less intense degree of local involvement does not mean the development approval process is especially simple or easy. Even for projects that do not require any rezoning, the mean LPAI of 1.67 indicates that many of these 'lightly-regulated' places have multiple entities that must approve the application. The modal response (at 32\%) reports two such entities; $58 \%$ of this group of respondents note that a local planning commission must give its blessing, with $42 \%$ indicating that a local council must do so. For projects that do require some type of zoning change, the LZAI value of 2.28 indicates that at least two entities are required for approval; $73 \%$ of these respondents note the local planning commission's approval is mandatory; $69 \%$ note the same for a local council, with $51 \%$ claiming that a local zoning board approval is required; no other entity listed in the underlying question (\#4) has more than a 6\% share.

Having less than the average degree of regulation also is associated with density controls. Density restrictions in the form of minimum lot size requirements exist in $94 \%$ of this group of 
communities. The most common size is for less than one-half acre per lot, although the mean subindex value of 1.92 implies that many of this (relatively) less-regulated group have larger minimum lot sizes.

Density restrictions may be omnipresent, but formal limits or caps on permitting or developing any type of residential property are not. The SRI value of 0.04 is the mean across six different 0-1 answers for the presence of such rules, which indicates that virtually none of this group reported any formal supply restriction.

Being relatively lightly regulated also means that jurisdictions are not likely to have an open space requirement (OSI), mandatory exactions fees (EI), or an affordable housing program (AHI). Affordable housing programs are especially rare among this group, as its mean of 0.02 indicates that only $2 \%$ of, or 1 -in- 50 , communities imposes any type of requirement pertaining to such housing. Open space requirements and exactions are more common, but only one-third report having the former and only one-fifth report the latter.

Finally, the typical time delay between submitting an application for a project and hearing a decision from the government is 3.7 months among this group of communities. That works out to 111 days presuming 30 days per month.

A second noteworthy pattern in the data is that to be more regulated implies stricter controls across the board, not just in one or two dimensions. This is indicated by the fact that all subindex values rise as one moves from left to right across Table 3. Table 4 then explains that places in the top quartile of the WLRURI2018 distribution report a high level of involvement by local public officials; 90\% indicated more than moderate levels of such involvement with over two-thirds claiming a 'very high' degree of involvement; 55\% of this group also reports greater than moderate levels of community pressure; and 1-in-5 reported at least one other important 
player in the local regulatory process. On average, these communities report more involvement by their state legislatures and their court systems, too. Thus, the underlying political and legal environment in which the regulatory process is managed is more intense than in lightly regulated places (with 'average’ places in between).

The same holds true for every other dimension by which we measure the degree of regulation. This is the only group for which the typical community has an open meeting requirement ( $\mathrm{LAI}=0.60$ ). Formal restrictions on supply still are quite rare even for this highly regulated group, but there are more entities that must approve (and thus, can veto) any given project. At least three entities must approve a project that does not require any zoning change (LPAI=3.22), while nearly four are typically required to approve anything that requires some type of variance (LZAI=3.69). On average, density controls are much more extreme for this group of communities, too. The modal community on this issue has a $2+$ acre minimum lot size restriction; $66 \%$ of this group reports a minimum of over one-half acre somewhere within its jurisdiction. Three-quarters of this group of the most highly-regulated places also have a formal open space requirement (OSI=0.76) and they typically impose exaction fee regimes on developers ( $\mathrm{EI}=0.75)$. Less than half have an affordable housing program, but the slightly more than one-third that do (AHI=0.36) is more than triple the share in the interquartile range, and is 18 times greater than in the most lightly-regulated communities. Project review times are more than twice as long compared to the lightly-regulated places, at 8.4 months or 252 days.

What differentiates an average from a lightly-regulated community in the United States is a somewhat higher intensity of involvement at the local and state political level, modestly more entities required to approval any type of project, modestly more stringent density controls in the form of larger minimum lot sizes, the widespread presence of open space requirements and 
exaction fees, along with about 40 more days needed to get a decision on a project application.

Thus, there is a fairly extensive regulatory framework in the places we rate as average in terms of overall strictness.

Finally, the data reported at the bottom of Table 3 show that the degree of regulation is increasing in local income, house value, and educational achievement of the population. However, the more tightly-regulated places in our sample do not have a higher share of white residents; in fact, they are five percentage points lower in white resident share. Finally, they are larger in terms of population and land area, as well as in terms of population density, but no causal relation between regulation and any of these variables is implied, of course.

\section{III.C. Regulatory Intensity Across Housing Markets}

Table 5 reports WRLURI2018 values for the 44 CBSAs with at least ten individual community responses to our survey. These are simple averages across each community within the relevant CBSA. These areas contain 150,827,922 people according to 2017 estimates from the American Community Survey (ACS). This is about $49 \%$ of the total population within CBSAs. This list also contains the 16 most populous metropolitan areas in the country, so the larger urban areas are well represented, but many less populated ones are not. ${ }^{13}$

The geographic concentration along the coasts of the most highly-regulated housing markets is obvious from the first eight names. The San Francisco CBSA has the most regulated housing market in the country by our measure. ${ }^{14}$ It and the New York City CBSA are the only

\footnotetext{
${ }^{13}$ The $17^{\text {th }}$ and $18^{\text {th }}$ ranked CBSAs are San Diego-Carlsbad (population 3,283,665; six of its communities responded to our survey) and Tampa-St. Petersburg-Clearwater (population 2,978,209; eight of its communities responded to our survey), respectively.

${ }^{14}$ The San Francisco CBSA does not include the San Jose-Sunnyvale-Santa Clara CBSA. There were only six communities from that latter market which responded to our survey. Their average WRLURI2018 value was 0.92, so this CBSA would rank $4^{\text {th }}$ if included separately.
} 
ones that have index values more than one standard deviation above the sample mean. Others in the top quartile of the WRLURI2018 distribution include the Providence (RI), Washington, DC, Seattle, Los Angeles, Riverside-San Bernardino, Miami (FL), and Phoenix markets. The Portland (OR) and Madison (WI) markets are also of note, as they have WRLURI2018 values within four-one hundredths of a standard deviation of the cutoff for the top quartile. Figure 1's plot highlights the strong regional pattern. Three groups of markets are presented: the top 11 (in red), the middle 22 (in blue) and the bottom 11 (in green). ${ }^{15}$

One other noteworthy pattern in the local market data is the high share of individual communities in coastal markets especially that are themselves very highly regulated by our measure (i.e., in the top quartile of the distribution of WRLURI18 values). Table 6 reports these shares for the same 44 CBSAs. If a market is in the top quartile of this group, it is likely that at least $50 \%$ of the responding communities within its metropolitan borders are themselves highly regulated. And, in the San Francisco and New York City CBSAs, the shares are three-quarters and two-thirds, respectively. Thus, the most intensely regulated CBSAs are not so because of a few ultra-restrictive outlier communities; rather there seems to be a high average level of regulation with a tight variance.

Among the markets in the interquartile range of this table, the share of highly-regulated communities averages from one-quarter to one-third. One can readily find individual jurisdictions that do not strictly regulate the supply of housing in these areas And, in the bottom quartile of these markets by WRLURI2018 values, the typical share is even lower-in the 10\%-

\footnotetext{
${ }^{15}$ Appendix 5 reproduces the rankings from our 2008 paper (WLURI2006) for comparison purposes. A quick perusal shows broad persistence in relative rankings in the sense that if a market was in the top third or one-half of the sample in the first survey, it is highly likely to be relatively highly ranked in the latest survey. However, there are some material moves individually, with the jump of various west coast markets towards the very top of the rankings. Regionally, that is the biggest change across the market-wide rankings over time.
} 
$20 \%$ range. Thus, there always are some highly-regulated jurisdictions within any metropolitan housing market that are themselves lightly regulated on average. However, one of the differences between lightly- and highly-regulated CBSAs appears to be the ease with which a typical household could find a community that does not strictly regulate the supply side of the market within its own borders.

\section{How Has the Regulatory Environment Changed Over Time?}

Because altering policy involves a formal legal process, we would not expect the regulatory environment to exhibit substantial high frequency change on a monthly or annual basis. But a decade-plus span seems long enough to see alterations if desired by the local populace or political leadership. Most of the survey responses are from 12-14 years apart, as the first Wharton survey was sent out in late 2004, with the last round of responses received as late as 2006. The second survey was conducted entirely within calendar year $2018 .{ }^{16}$

This time span provides the opportunity to answer important questions. One is whether the Great Recession precipitated a broad change in attitude across American housing markets that led to less restrictive local residential land use regulation environments. A related question is whether there are specific places, or perhaps more importantly overall housing markets, that once strictly regulated the supply side of the housing market, but have since reversed course and undone such regulation.

\footnotetext{
${ }^{16}$ In this section, we use data on all responses to questions, even if the locality did not fully answer all questions so that we could not calculate an aggregate WRLURI2018 value for the place. The full underlying sample contains observation on 2,844 communities, 372 of which did not respond to one or more questions used in our aggregate index creation. The final dataset that we will post contains all 2,844 observations on communities who responded partially or in total to our survey.
} 
We measure change in the local regulatory environment by comparing answers to a variety of questions that are identical (or close to identical) across the two surveys. Moreover, we have the ability to see whether changes are due to selection effects from a different set of communities responding to each survey. In addition to the full sample of respondents who answered a given year's survey, we typically have from 750-900 communities that answered any given question in both surveys, with about 500 having answered all questions fully across both surveys.

We start by examining the responses to a series of questions that help us identify whether the strictness of different local regulations themselves changed over time. Our first case discussed below involves whether there was a change in the number of entities needed to approve a project that requires rezoning. In addition to reporting the full range of answers to this question based on the cross section of communities that responded in each respective year, we also report responses from the smaller panel of communities that answered the question in both surveys. We then compute whether the number of entities required for project approval changed across surveys by subtracting the number from the 2006 survey from that reported in the 2018 survey (for those who answered both surveys, obviously). Hence, positive (negative) values reflect increases (decreases) in the number of entities required for approval, with no change differencing out to zero. We then classified the full range of possible responses into declines, no change and increases. ${ }^{17}$

Each of the nine panels in Figure 2 reports these three pieces of information in chart form on a particular feature of the regulatory process. Before delving into the individual regulations

\footnotetext{
${ }^{17}$ Specifically, if intensity of regulation increased by any amount over time, the change was coded as a +1 in Figures 2-4 below; analogously, if intensity of regulation decreased by any amount over time, the change was coded as a -1; no change was coded as a zero.
} 
themselves, it is noteworthy that the distributions of responses reported in the first column (based on all respondents to any survey), as well as those in the second column (based only on the smaller number of communities that answered both surveys), always look quite similar. This is comforting because it suggests that there are not strong selection effects in who answered the underlying questions in both surveys that could bias our conclusions.

The data reported in the top panel of Figure 2 on the number of entities that must approve a project requiring rezoning are drawn from answers to the first part of Question 4 from the 2018 survey and the answers to Question 2 from the 2006 survey. Researchers using the survey response data should take care in making this comparison because the 2018 survey asked about more entities that might have approval rights (9 in 2018 versus 6 in 2006). Hence, we standardize on the six entities about which we asked in both surveys. ${ }^{18}$ Regardless of the sample, the share of communities reporting that there was only one entity required to approve the project fell by about ten percentage points, with a similar fall for those claiming two entities were required. These 20 share points are shifted up the distribution, with the bulk of the change (from 16-19 points depending upon the sample) observed on a sharply increased share of places saying that by 2018 three entities were required to approve any project requiring rezoning. Among the group that answered both surveys (middle column), in 2006 slightly more communities reported only one entity required for approval than reported three were needed; just over a decade later, the share reporting three was nearly four times that reporting only one. This is further reflected in third plot in the panel which shows that $45 \%$ of communities that responded to both surveys increased the number of entities required for project approval versus only $15 \%$ that lowered the number.

\footnotetext{
18 These entities were the Local Planning Commission, Local Council, County Board, Environmental Review Board, Public Health Board, and Design Review Board.
} 
The next panel of Figure 2 shows the same type of shift did not occur for "by right" projects (those not needing rezoning) ${ }^{19}$ As discussed earlier in the paper, the modal number of entities required to approve this type of project is two, and the share of communities requiring three did not change much. The share of those who increased the number required is greater than those who decreased the number, but only by 3 percentage points (34\% versus 31\%; see the final plot in the second panel).

The next two panels show that the scope and scale of density controls in the form of minimum lot sizes increased materially since the first survey. Minimum lot size restrictions were widespread at the time of the first survey, with $84 \%$ of communities having them in at least one neighborhood. That share is now $94 \%$, so they have become virtually omnipresent across America. ${ }^{20}$ Perhaps more striking is the increase in the size of the largest minimum lot size regulation within a given jurisdiction. The fourth panel of Figure 2 shows that the share of communities experiencing an increase in their largest minimum lot size was double that which saw a decline ( $41 \%$ versus $20 \%$, with the rest unchanged; see the third plot in the panel). ${ }^{21}$ The modal minimum still is under one-half acre, but the share with a larger minimum increased from 39\% in the 2006 survey to 52\% in the 2018 survey (for the smaller set of cities that answered both surveys; the increase is even greater using the changes reported by the two cross sections). While over half of communities now have a density control requiring at least one-half acre lot sizes somewhere in their jurisdictions, over one-third have a 1-acre+ minimum (35\% in 2018 versus $25 \%$ in 2006; see the middle panel).

\footnotetext{
19 These results compare and contrast responses to the second part of Question 4 in 2018 and Question 3 from the 2006 survey.

20 These data are from Question 7a in 2018 and Question 6 in 2006.

21 These data are from Question 7b in 2018 and Question 6 in 2006.
} 
The rest of the results reported in Figure 2 do not show widespread increases in adoption of other regulations or increases in the strictness with which a regulation is imposed. That said, with one exception (the use of impact fees which is discussed below), there is no evidence that the typical community is abandoning these other regulations or reducing their severity. One clear example of this pattern involves the use of open space requirements. ${ }^{22}$ The fifth panel of Figure 2 shows almost no change in the percentage of communities that have such programs. It still is the case that the typical community has such a requirement, as from 57\%-59\% of communities report having it depending upon the underlying sample and survey year. However, over two thirds did not change their policy on this issue between the survey years; and of the $30 \%$ that did, one-half imposed a new open space program and one-half eliminated one that was in existence before 2018.

There is a similar pattern for affordable housing programs, although they have never been widespread (panel 6). ${ }^{23}$ The share of communities reporting having one is never above $20 \%$ in any year or sample, and it has declined slightly over time. Over four-fifths of communities report no change over time on this policy issue. Of the $17 \%$ that did change, slightly more than one-half reported abandoning the policy. Overall, affordable housing initiatives remain fairly rare and tend to be confined to larger cities or smaller suburbs in very high cost housing markets.

The one case for which we see a clear drop in the use of a regulation involves imposing exactions on homebuilders (i.e., impact fees to pay for allocable shares of infrastructure-related costs). The results plotted in the seventh panel of Figure 2 show nearly a 25-percentage point drop in the use of such fees, from just over three-quarters of communities in 2006 to barely one-

${ }^{22}$ These results compare responses to Question 9b from the 2018 survey and Question 6 from the 2006 survey.

${ }^{23}$ These results compare responses to Question 9a in the 2018 survey and Question 6 in the 2006 survey. 
half in the 2018 survey. The final plot in this panel shows that more than four times as many communities dropped this type of program than implemented it between our surveys.

The eighth panel reports results for hard caps on permitting or development. These data are from Question 8 in 2018 and Question 5 in 2006. For this regulation, we created an aggregate variable that is coded as a 1 if a community had any one of the six possible supply caps in a given survey year. The change up or down is computed as the net change after summing across all categories. These types of regulation have been and remain extremely rare. No more than $4 \%-8 \%$ of communities have any one of the six types of restrictions posed in the survey questions. And, there is little change in whether they are in use over time.

The ninth and final panel reports results for changes in review times. The underlying data are from two different pairs of questions: (a) Question 20 in 2018 and Question 12 in 2006, which ask about the typical review times for different types of single- and multifamily projects that need rezoning, but are not part of a subdivision development; and (b) Question 22 in 2018 and Question 13 in 2006, which ask for the same information about projects that are part of a subdivision development. For consistency, we report findings for all six different types of projects: (a) $<50$ unit single family developments requiring rezoning, but not in a subdivision development; (b) >50 unit single family developments requiring rezoning, but not in a subdivision development; (c) multifamily development requiring rezoning, but not a subdivision development; and (d)-(f) which are the analogous versions of (a)-(c), each involving a subdivision.

These results indicate that there is relatively little change in the reported delays for different types of projects. This is the case for the typical single- or multi-family project that is not part of a subdivision development, where average review times of 4-5 months hold in both 
surveys. ${ }^{24}$ The share of communities reporting increases in review times are slightly greater than those reporting declines, but only by 2-3 percentage points. Those gaps are a bit larger (5-6 points) if a project is part of a subdivision, so the evidence for a modest increase in review times is stronger there. Average review times across the different types of subdivision projects increased by $10 \%-15 \%$ across the two surveys. The final plot in this panel, which reports the net change in whether review times fell, stayed the same, or increased across all six options shows that a slightly greater share of communities experienced some increase in review times than did those who reported shorter time (45\% versus $39 \%$ ). As suggested above, this difference is driven by rising review times for subdivisions.

A handful of other questions allow us to see whether the intensity of involvement by local and state actors changed over time. The very different points in the business and housing cycle at which the surveys were conducted might lead one to suspect a sharp drop in interest over time on the part of the public, public officials and the courts. The 2006-7 responses come just before the peak of what we now know to be the greatest housing boom in the post-World War II era, so it is not unreasonable to believe that local officials and populaces were especially concerned then about a variety of issues ranging from affordability to external effects from high rates of new construction in many markets. While some of the results reported in Figure 3 are consistent with this story, even the decline in community pressure depicted in that figure's second panel is modest. Overall, the findings on this part of the regulatory environment are one of continuity.

\footnotetext{
${ }^{24}$ These questions are not identical across surveys, so some caution in interpreting the results is in order. In the first survey, we just asked about each product type. In the 2018 survey, we asked about 'by right' and 'not by right' projects within each product type. Our conclusion is based on averaging the results for 'by right' and 'not by right' responses for single-family and multi-family, respectively, and then comparing those results to the 2006 numbers. Essentially, we are presuming the 2006 results are an average of review times for 'by right' and 'not by right' projects within each product type.
} 
There are two identical questions in each survey’s LPPI subindex. One asks about the extent of involvement by a local council or managers; the other is about the degree of community involvement. There is only one common question across surveys in the SPII index—regarding the degree of involvement of the state legislature. The CII subindexes are the same across surveys, with two questions asked about the level of the local and state courts's involvement in the regulatory process. ${ }^{25}$

The top panel of Figure 3 indicates that it was, and remains, typical for some type of local council to be fairly heavily involved in the regulatory process. However, the share reporting the highest level of involvement has declined over time: the share of communities answering that involvement was heavier than average fell from $85 \%$ to $72 \%$ across the full samples of the two surveys, and from $87 \%$ to $74 \%$ in the subset of 814 communities for which we have answers to this particular query in both surveys. This pattern also is consistent with the third figure in that panel showing one-third of communities reporting declines in the intensity of involvement versus one-fifth reporting increases; the modal response was for no change (44\%).

The second panel shows that heavy involvement by local pressure groups still is not a truly widespread phenomenon across the nation, and its perceived importance has declined modestly over time. In the first survey, just over $40 \%$ of communities responded that local pressure groups exhibited higher than moderate degrees of involvement. In the 2018 survey, this share falls by 10-12 percentage points to just under 30\%, regardless of the sample considered. As noted above, this could be due to the very different points in the cycle at which the two

\footnotetext{
${ }^{25}$ The underlying data are from Question 3 in the 2018 survey and from Question 1 in the 2006 survey. The specific question is "In your community, how involved are the following in affecting residential building activities and/or growth management procedures?” Respondents were then asked to evaluate the role of each of the five actors noted above.
} 
surveys were conducted. The share of decliners also modestly exceeds increasers for this variable, too, as indicated by the third plot in this panel.

There is very little change over time in the distribution of intensity of involvement by the state legislature or either of the state or local court systems (see the next three panels of Figure 3). There is virtually no change in the typical response or in the interquartile range of responses over time for these variables. In the typical community, the state legislature is not viewed as intensely involved; the $75^{\text {th }}$ percentile response reports only a moderate level of involvement. This has not changed over time and holds for the subset of places that responded to both surveys. The state and local court systems are considered even less involved on average, and there is no change over time in the distribution of responses for either court system. It also is common for communities to respond that there was no change in the typically low level of court involvement over time. ${ }^{26}$ In sum, much of the evidence suggests relatively little change in the nature of local or state political and legal involvement in the regulatory process, with some communities indicating a modest decrease in participation by the public and its elected officials.

To develop additional metrics of how the two parts of the regulatory environment changed, we aggregate across the different items plotted in Figures 2 and 3. The first plot in Figure 4 shows the distribution of what we term the Regulation Change Index. This captures the net change over time in the nine facets of regulation investigated in Figure $2 .{ }^{27}$ This starts as the simple sum of the change in the response values for each of the nine underlying questions to arrive at a net change. Thus, if five of the questions indicated an increase in strictness of regulation, while three indicated a decrease in strictness, and one was unchanged, the Regulation

\footnotetext{
${ }^{26}$ While this is true in aggregate, there is some interesting regional variation, with California communities in particular noting a marked increase in involvement by the state legislature, as well as the courts.

${ }^{27}$ The last index reported in the final panel of Figure 2, which sums across the six different review time variables, is used in the creation of this index.
} 
Change Index would have a net value of $+2(5-3+0=2)$. For the purposes of this plot, we considered all net negative (positive) values as indicative of a decline (increase) in regulatory strictness, with a zero indicating no change. The shares of communities in each category are reported in the bar charts in Figure 4.

The top chart shows that $49 \%$ of communities reported a net increase in regulatory strictness versus $33 \%$ that reported a decline (with $18 \%$ being unchanged in net terms). Of the nearly one-half of communities with positive net changes in their Regulation Change Index, 34\% (or $13 \%$ of all communities in the sample) increased by one regulation on net; the other $66 \%$ ( $25 \%$ of the total) increased by two or more. The most likely regulations to be newlyimplemented or strengthened are increases in the number of entities required to approve a project needing rezoning (63\% of those with net positive changes reported such an increase), increases in project review times (also 63\%), and more entities required to approve 'by right' projects not needed rezoning (54\%). Note that these are all related to the regulatory process, rather than formal policy requirements. With regard to the latter, roughly one-quarter of this group adopted minimum lot sizes anew or imposed a larger minimum since the first survey. The other regulations were more rarely increased. If one of these communities decreased a regulation, it was likely to be in the form of reduced project review times (25\%) or eliminating impact fees (20\%). By definition among this group, such a change was more than counterbalanced by increases in other regulations.

Of the one-third of all communities whose Regulation Change Index declined on net, the most likely reasons were falls in review times (73\% of that subsample) or a decline in the number of entities required to approve a 'by right' project. No other policy was eliminated or 
loosened by more than one-half of these communities, although impact fees were eliminated by $44 \%$ of this group. ${ }^{28}$

The bottom chart in Figure 4 reports what we call the Political/Legal Change Index. This captures the net change in intensity of involvement across the five underlying questions described in Figure 3. It is calculated in the same way as the Regulation Change Index, so that if two of the questions indicated increases in intensity, two indicated decreases, and one was unchanged, the net change reflected in the Political Change Index is zero $(2-2+0=0)$. As above, we then consider all net negative (positive) values to be indicative of a decline (increase) in the intensity of involvement by political/legal actors, with a value of zero indicating no change.

The pattern here is almost opposite of that for the Regulation Change Index. Half of the communities in the panel that answered both surveys reported a net decline in intensity of involvement according to our Political/Legal Change Index. Of this group, 29\% (14\% of all communities) decline by one on net. The likelihood of decline was similar across all five potential factors (from $49 \%$ to $60 \%$ of any given factor showed a drop in intensity of involvement among this group of communities). Of the roughly one-third that did experience a net increase in their Political/Legal Change Index, the most likely reason was to have reported an increase in community pressure (62\% of this subsample).

We are now in a position to answer the first question posed at the beginning of this section: did the Great Recession set the stage for a new attitude towards residential building that resulted in lower regulatory barriers on average? No, it did not. Moreover, in a couple of important areas, many (but certainly not all) local regulatory regimes were strengthened over the past decade. On average, the approval process became more cumbersome, as reflected in the

${ }^{28}$ Of this group with net declines in their Regulation Change Index, 29\% fell by one on net; naturally, the other $71 \%$ declined by more. 
number of bodies with veto rights over projects, and land use policy became more stringent, as evidenced by increasing density controls on the intensive and extensive margins (i.e., more extensive adoption of minimum lot sizes and increases in minimums among places that had them before). More communities reported declines in intensity of involvement by local officials than reported increases, but even so, roughly three-quarters of all places still face what they label as 'higher than average' involvement by those officials. It also is the case that there has not been a sea change in terms of community pressure: moderate involvement is still the norm. On net, the local regulatory environment looks to be somewhat more restrictive now than it was just before the housing bubble burst, although there do not appear to have been truly major changes in its nature. There is some interesting regional variation in these outcomes, but the pattern is broad in the sense it characterizes most of the country, not just the northeastern and west coasts of the nation. We turn to that evidence in the next subsection.

Before doing so, we note one other matter raised by these findings. By our metric, about one half of all communities in the Regulation Change Index increased regulation, one-third decreased, while only 18 percent showed no net change. This raises the question of where are the communities located that changed their regulatory environment? Are all the 'increasers' in the highly regulated coastal markets? Are the 'decreasers' concentrated in the slow-growing parts of the country in the so-called Rust Belt? No, they are not; they are everywhere as the plots in Figure 5 show. The top chart identifies (in orange) every CBSA in our sample that contains at least one community that experienced a net increase of +1 or more in its Regulation Change Index. These areas certainly include virtually everywhere along the so-called Acela Corridor running from Boston to Washington, D.C. on the east coast and each of the big metropolitan areas along the west coast. However, they encompass many areas in between (as well as north 
and south), including many CBSAs located in the Rust Belt. The bottom chart then plots CBSAs with at least one respondent community that had a net decrease of -1 (or more) in its Regulation Change Index. 'Decreasers' are everywhere, too. The plots are not identical, but they look quite similar. Even in the most highly (lightly) regulated housing markets in the country, a small number of its communities became less (more) strictly regulated over time.

\section{IV.A. Variation in the Regulatory Environment Across Time and Space}

Because changes in the degree of regulation can only be measured within the set of communities that answered both surveys, we are left with a very small number of places per market to measure the degree of change at the CBSA level. Among the largest metropolitan areas, Chicago had the largest number of communities that responded to both surveys—45, but not all of them answered each question fully. Dallas was next at 29, with Los Angeles at 21 and Detroit at 20. Other than the New York CBSA, no other market had more than 14 respondents to both surveys. Given such small numbers, one community changing implies large percentage impacts in most housing markets.

Because this could be due to simple measurement error or noise with respect to one or two communities, we choose to combine CBSAs that themselves are similar and report aggregate results for those regions. We create our own regional groupings because the Census definitions end up combining markets that are quite different from one other for the purposes of this paper (e.g., the Modesto and San Francisco CBSAs are in the same state, but their metropolitan areas could not be more different from a land use regulation perspective). Our eight synthetic regions are as follows:

(a) West Coast: includes every CBSA that physically touches the Pacific coast, plus Portland, OR; there are 11 CBSAs in our sample in this region; 
(b) East Coast: includes six CBSAs that touch the Atlantic Ocean, ranging from Washington, D.C. to Portland, ME;

(c) Sunbelt: includes 75 CBSAs from the 11 states of the old Confederacy plus, Arizona, Kentucky, New Mexico and Oklahoma;

(d) Midwest: includes 37 CBSAs in Iowa, Illinois, Kansas, Minnesota, Missouri, Nebraska, North Dakota or South Dakota;

(e) Rustbelt: includes 28 CBSAs in Indiana, Michigan, Ohio or Wisconsin;

(e) Northeast-Not Coastal: includes 30 CBSAs in Connecticut, Delaware, Maryland, Massachusetts, Maine, New York (other than the New York City CBSA which is in East Coast), and Pennsylvania;

(g) Mountain: includes 14 CBSAs in Colorado, Idaho, Montana, Utah or Wyoming;

(h) West Coast-Not Coastal: includes 17 CBSAs in the states of California, Oregon and Washington that do not physically touch the Pacific Ocean.

Table 7 reports the share of communities in each region by whether their Regulation Change Index had a net increase, decrease or stayed the same. Column 1's figures illustrate that the increasing degree of regulation documented above is fairly widespread geographically. Five of our eight regional areas, including the geographically broad-based and heavily populated Sunbelt region, report more than half their communities saw net increases in our Regulation Change Index. No more than one-third experienced net declines, and the share is closer to or less than one-fifth in the West Coast and East Coast regions specifically. Only in the lightlypopulated Mountain region did the share of communities whose Regulation Change Indexes declined on net exceed those that increased. Responses were quite balanced among places within Midwest and Rustbelt region CBSAs, so there is no evidence of any meaningful reduction on average in regulatory strictness even in those areas with lower economic growth in recent years. 
The analogous data in Table 8 show that the aggregate decline in the Political/Legal Change Index is also widespread geographically. Only in the West Coast and West Coast-Not Coastal regional areas is the share of communities with negative net changes in this subindex not greater than the share with positive net changes. The share with negative net changes is above $50 \%$ in the East Coast, Midwest, Rustbelt and Mountain areas, and it is at $49 \%$ in the NortheastNot Coastal and Sunbelt regions. Lower political and legal pressure points did not translate into materially less strict regulation in most parts of the country.

There is no evidence that markets (or regional groupings of markets with our limited data) that formerly were highly regulated have become less so over time. In fact, the coastal regions have tended to become even more regulated over time. And, it is arguable that the overall degree of regulation has increased on average even in Sunbelt markets. The only region where regulation appears to have declined on net is in the Mountain region, but its markets were not highly regulated according to our previous survey.

\section{Conclusion}

The regulatory environment for housing is complex and varied across markets. Explicit limits on the number of units that can be supplied in a jurisdiction within a given time period are quite rare, and are present in only $6 \%$ of the communities responding to our new survey. Local governments do care about this process, however, as evidenced by the fact that $74 \%$ of the jurisdictions within a CBSA answered that their local government was more than moderately involved in the regulatory process. Local governments typically have multiple entities (review boards and the like) that must approve any project, including ones that will provide housing very similar to that which already exists in the community. More than two project-approving entities 
is now the norm across the country. Density restrictions have spread everywhere, and it is no longer uncommon to see a one acre+ minimum lot size restriction in at least one neighborhood within a community. The range of regulatory tools include impact fees (i.e., exactions) and space dedications by developers, along with affordable housing requirements in some places (about $14 \%$ of the communities in our survey). Significant regulatory delays in project approval remain the norm across communities. All-in-all, our new survey paints a picture of high potential regulatory costs.

That raises the critical question of how impactful local housing development regulation is on prices and quantities in different markets. On Monday, January 15, 2020, we will post the underlying data so that researchers may use it to try to answer that and other questions. 


\section{Selected References}

Albouy, D., \& Ehrlich, G. (2018). Housing productivity and the social cost of land-use restrictions. Journal of Urban Economics, 107, 101-120.

Been, V., \& Ellen, I. G., \& Gedal, M., \& Glaeser, E., \& McCabe, B. J., (2016). Preserving history or restricting development? The heterogeneous effects of historic districts on local housing markets in New York City. Journal of Urban Economics, Elsevier, vol. 92(C), pages 16-30.

Brueckner, J. K., \& Singh, R. (2018). Stringency of Land-Use Regulation: Building Heights in US Cities.

Emrath, P. (2016). Government Regulation in the Price of a New Home. Special Study for Housing Economics, National Association of Home Builders, Washington, DC.

Ganong, P., \& Shoag, D. (2017). Why has regional income convergence in the US declined?. Journal of Urban Economics, 102, 76-90.

Gedal, M., \& Ellen, I. G. (2018). Valuing urban land: Comparing the use of teardown and vacant land sales. Regional Science and Urban Economics, 70, 190-203.

Glaeser, E., \& Gyourko, J., (2018). The Economics Implications of Housing Supply. Journal of Economic Perspectives, 32 (1): 3-30.

Glaeser, E., and Ward, B. (2009). The Causes and Consequences of Land Use Regulation: Evidence from Greater Boston, Journal of Urban Economics, 65: 265-278.

Glickfield, M., \& Levine, N. (1991). Growth controls: regional problems—local responses. Cambridge, MA: Lincoln Institute of Land Policy.

Gyourko, J., \& Molloy, R. (2015). Regulation and housing supply. In Handbook of regional and urban economics (Vol. 5, pp. 1289-1337). Elsevier.

Gyourko, J., Saiz, A., \& Summers, A. (2008). A new measure of the local regulatory environment for housing markets: The Wharton Residential Land Use Regulatory Index. Urban Studies, 45(3), 693-729.

Jackson, Kristoffer (2016). Do land use regulations stifle residential development? Evidence from California cities. Journal of Urban Economics, 91, 45-56.

Jackson, Kristoffer. (2018). Regulation, land constraints, and California’s boom and bust. Regional Science and Urban Economics, 68, 130-147.

Lin, D., \& Wachter, S. M. (2019). The Effect of Land Use Regulation on Housing Prices: Theory and Evidence from California. Available at SSRN 3363947.

Linneman, P., Summers, A., Brooks, N., \& Buist, H. (1990). The state of local growth management. Wharton Real Estate Center Working Paper, 81.

Pendall, R., Puentes, R., \& Martin, J. (2006). From traditional to reformed: A review of the land use regulations in the nation's 50 largest metropolitan areas.

Turner, M. A., Haughwout, A., \& Van Der Klaauw, W. (2014). Land use regulation and welfare. Econometrica, 82(4), 1341-1403. 
Figure 1: Regional Variation in Land Use Regulation

44 CBSAs with $>=10 \mathrm{Obs}$

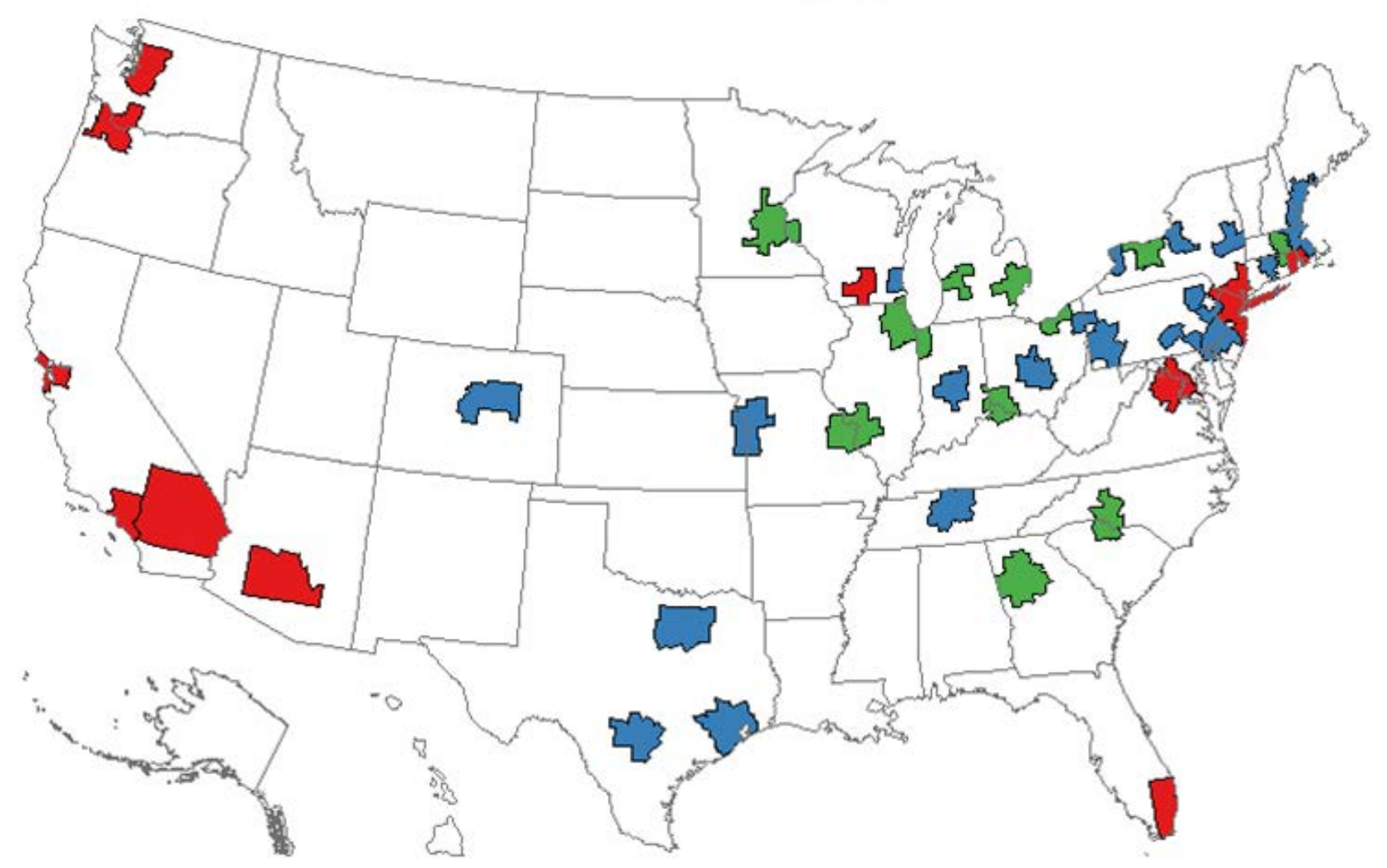

Red - Top 11 WRLURI2018 Values

Blue - Middle 22 WRLURI2018 Values

Green - Bottom 11 WRLURI2018 Values 
Figure 2: Changes in Regulatory Restrictions, 2006-2018

All Communities Answering a Survey

Communities Answering the Question in Both Surveys

Panel 1 - \# of Approvals for Project Requiring Rezoning
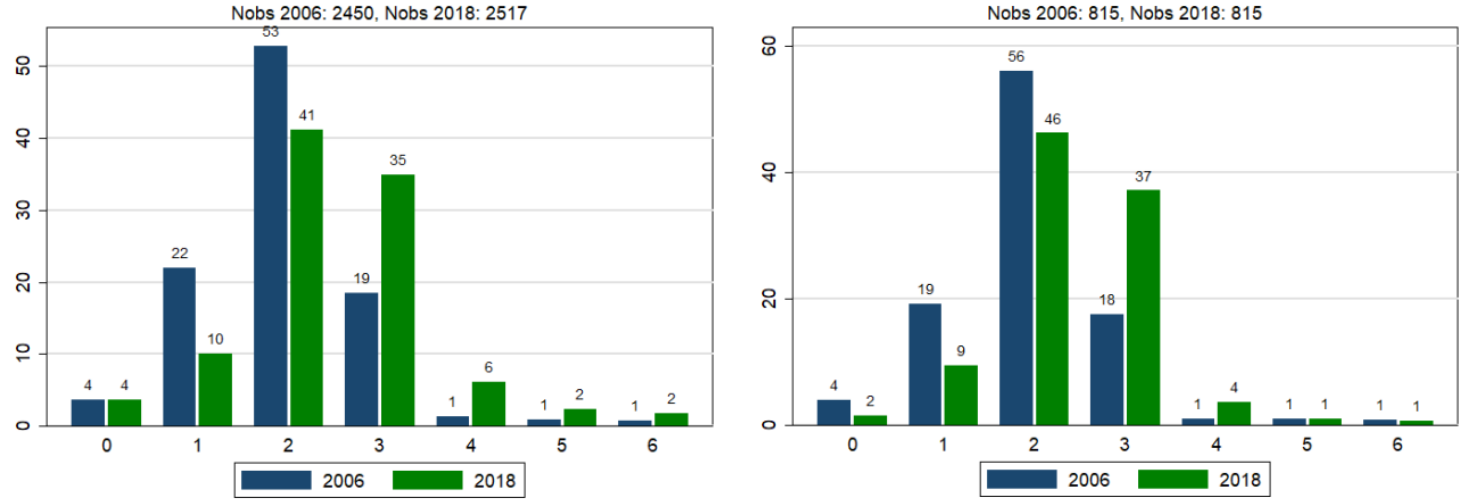

Panel 2 - \# of Approvals for Project not Requiring Rezoning (“By Right”)
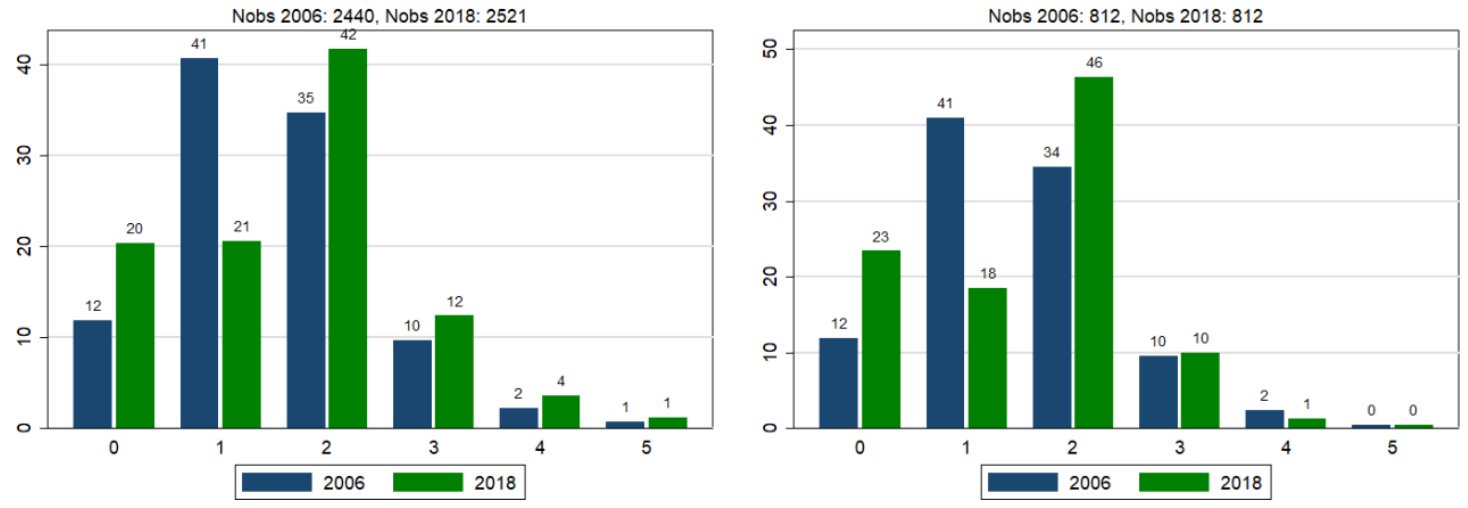

Share Decreasing (-1),

Staying the Same (0), Increasing (1)
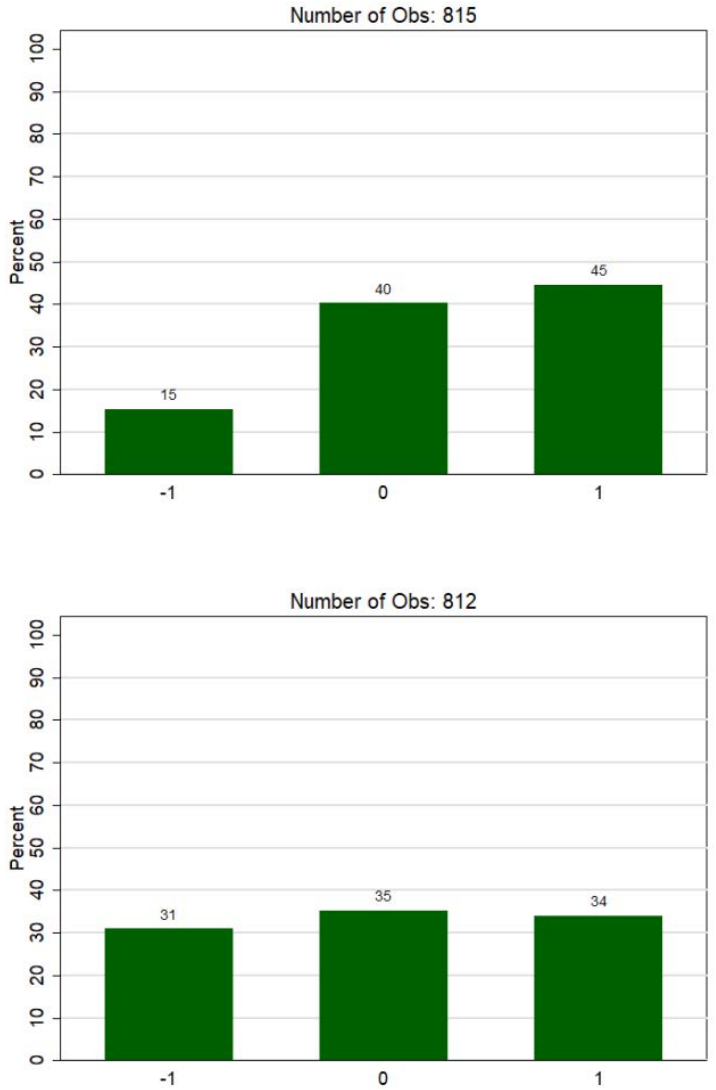


\section{Figure 2 (cont'd.)}

All Communities Answering a Survey

Panel 3 - Adoption of Minimum Lot Size, 0 = No Requirement 1= Requirement

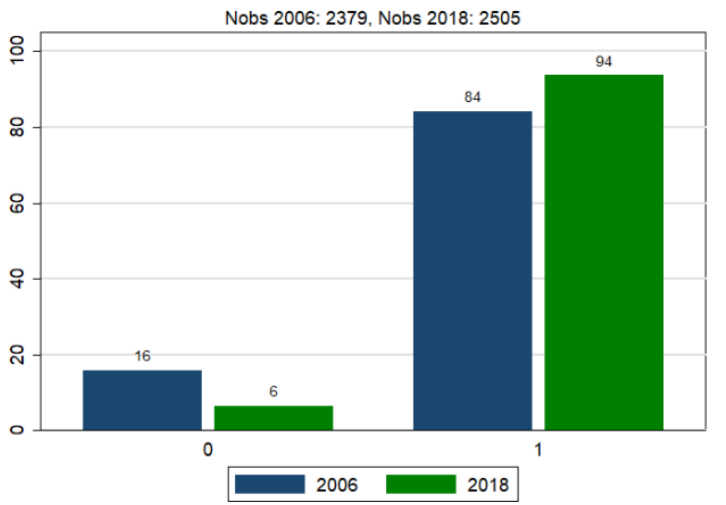

Communities Answering the Question in Both Surveys
Share Decreasing (-1),

Staying the Same (0),

Increasing (1)
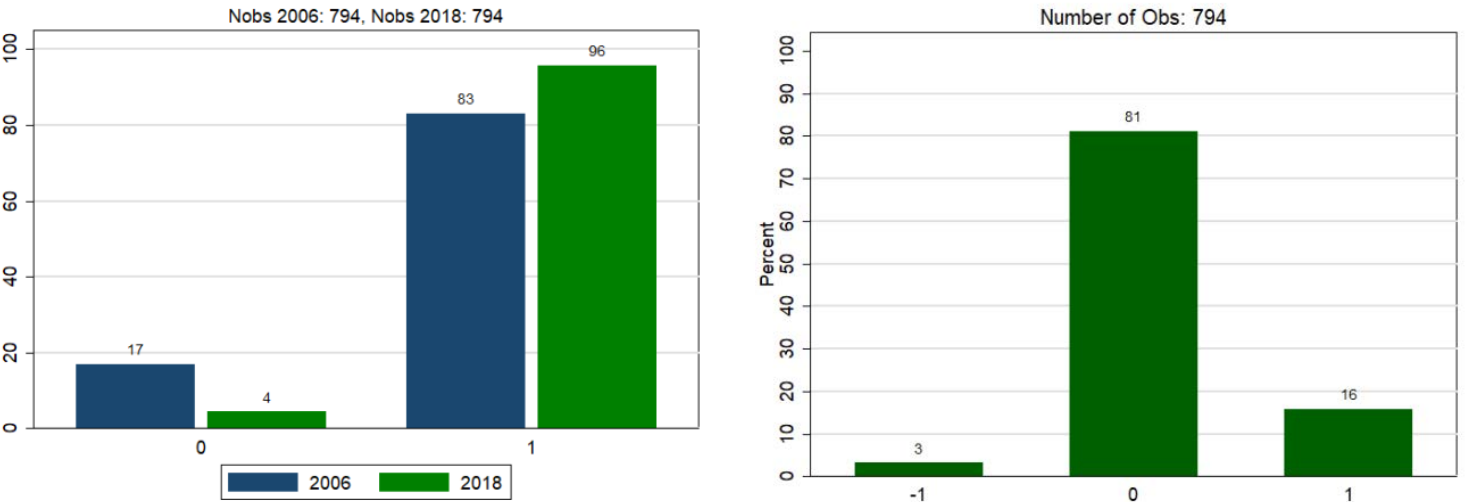

0
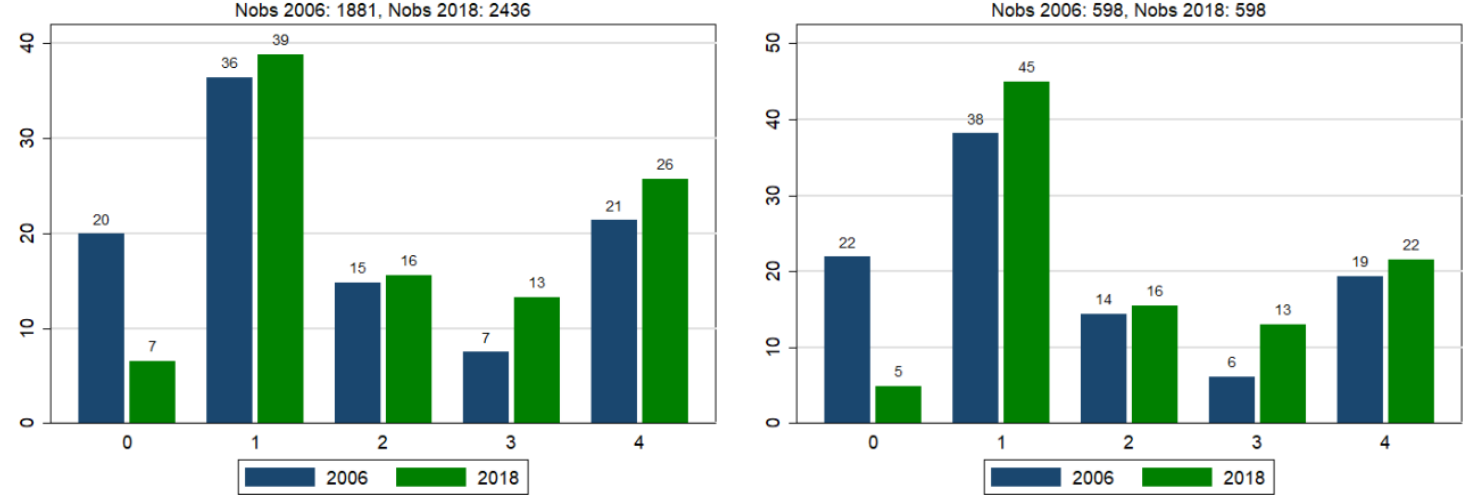

Number of Obs: 598

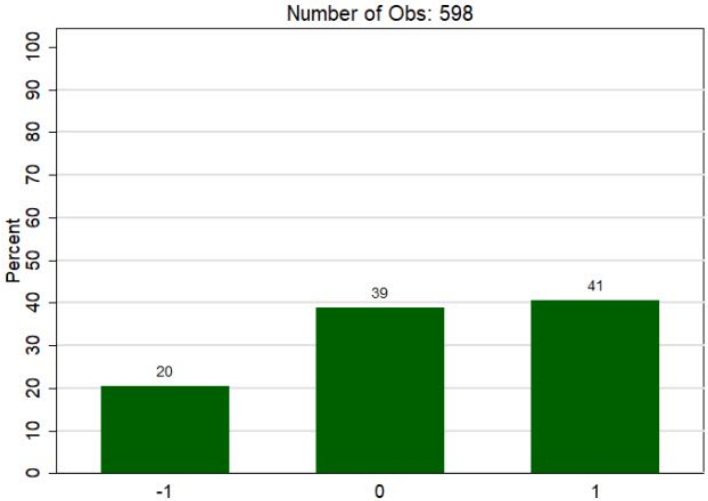




\section{Figure 2 (cont'd.)}

All Communities Answering a Survey

Communities Answering the Question in Both Surveys

Panel 5 - Open Space Requirement for Builders, 0 = Not Required, $1=$ Required
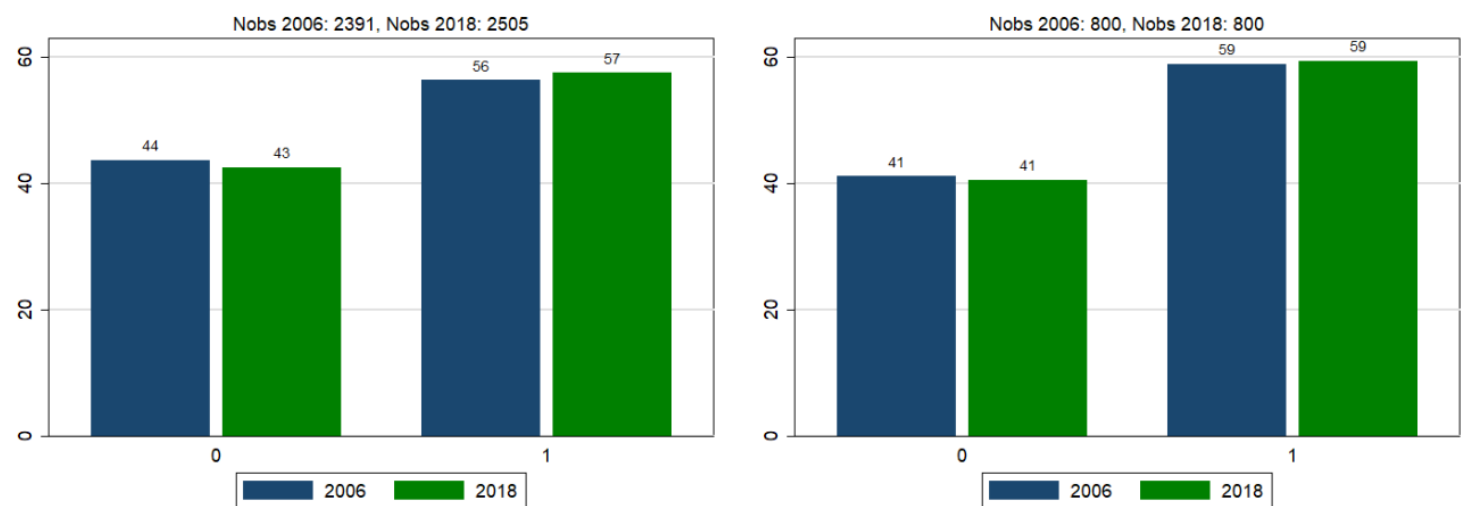

Panel 6 - Affordable Housing Requirements, 0 = Not Required, 1= Required
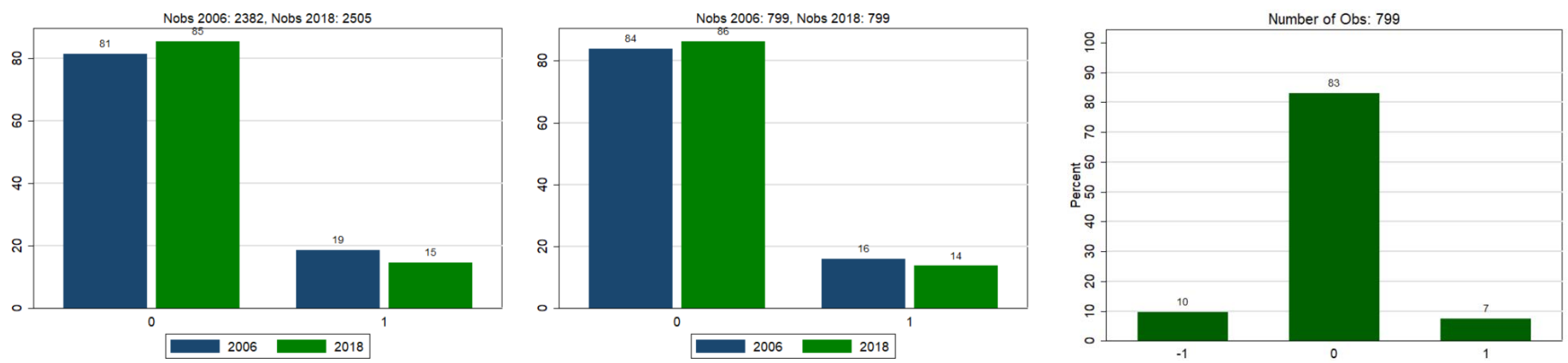


\section{Figure 2 (cont'd.)}

All Communities Answering a Survey

Panel 7 - Exaction / Impact Fee Requirements, 0 = Not Required, $1=$ Required
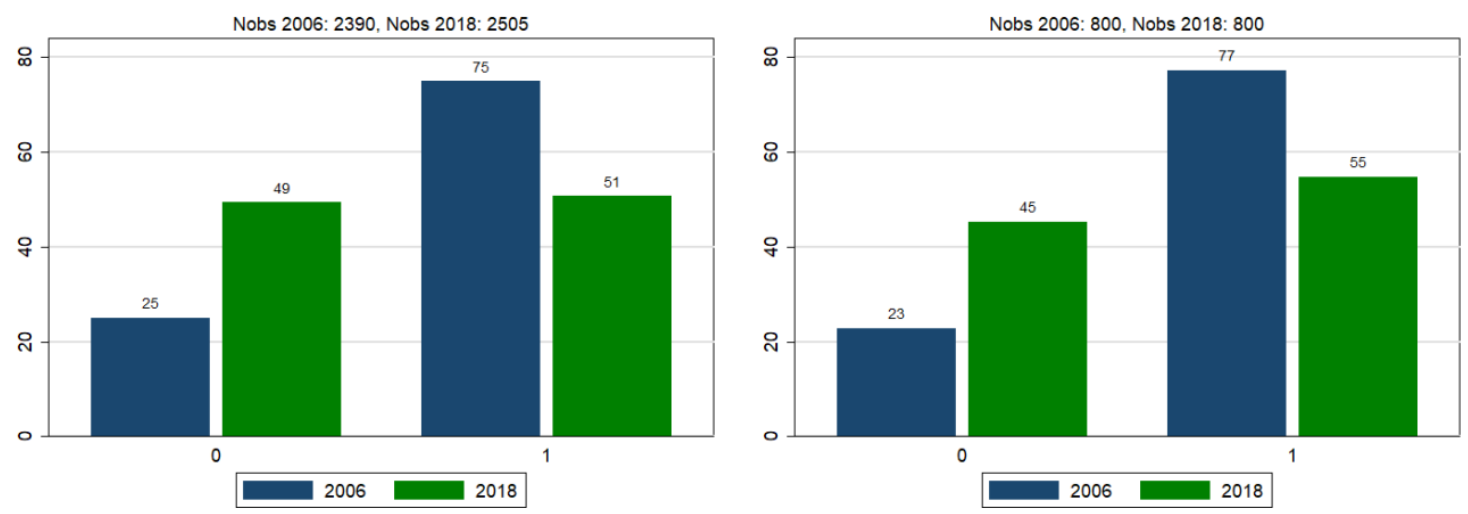

Panel 8 - Hard Caps on Permitting of Building, 0 = No Hard Caps on any Building Type to 6 = Hard Caps on All Building Types Surveyed
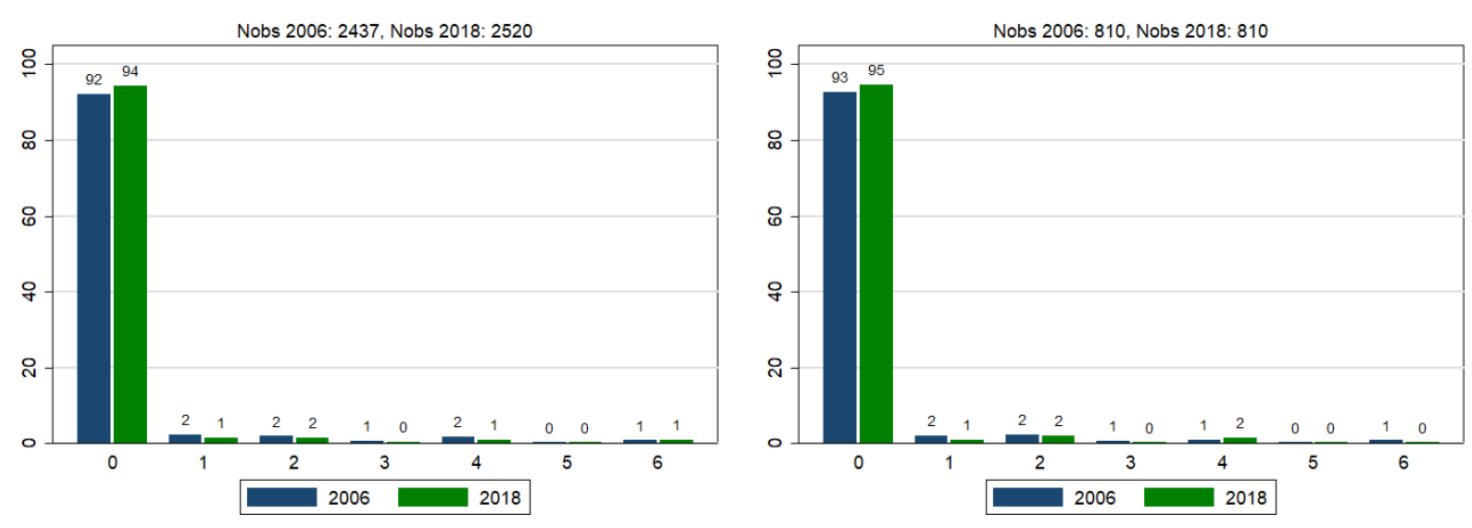

Share Decreasing (-1),

Staying the Same (0),

Increasing (1)

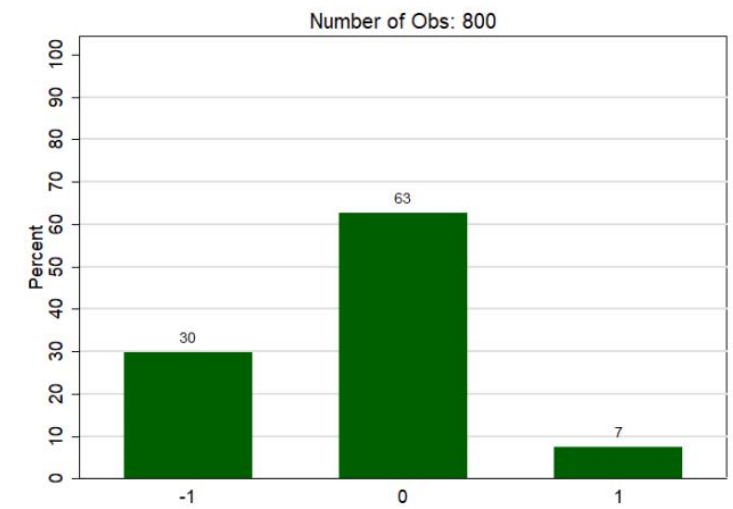

$-1$

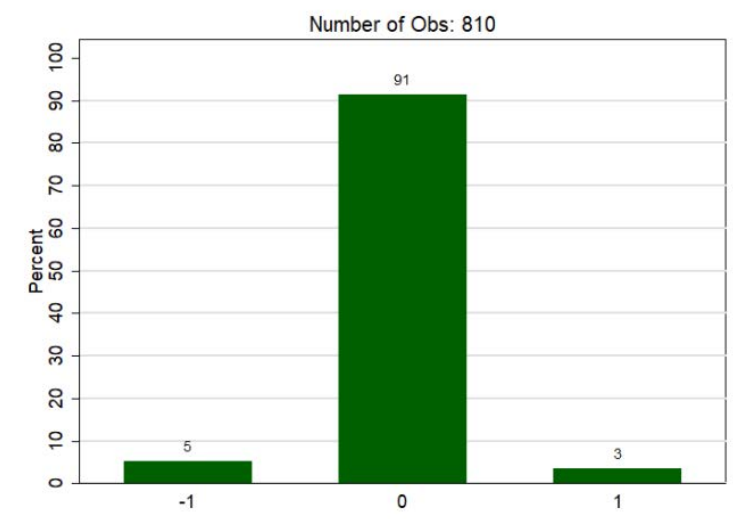




\section{Figure 2 (cont'd.)}

\section{All Communities Answering a Survey}

Panel 9 - Project Review Times, in Months Single Family less than 50 Units, Rezoning

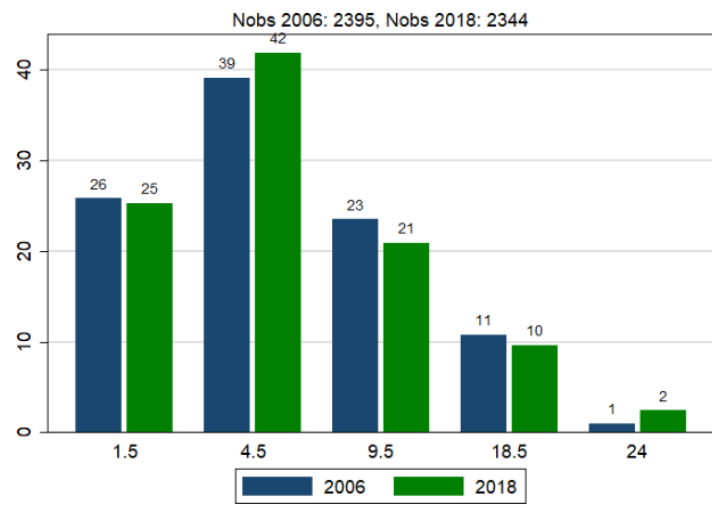

Single Family greater than 50 Units, Rezoning

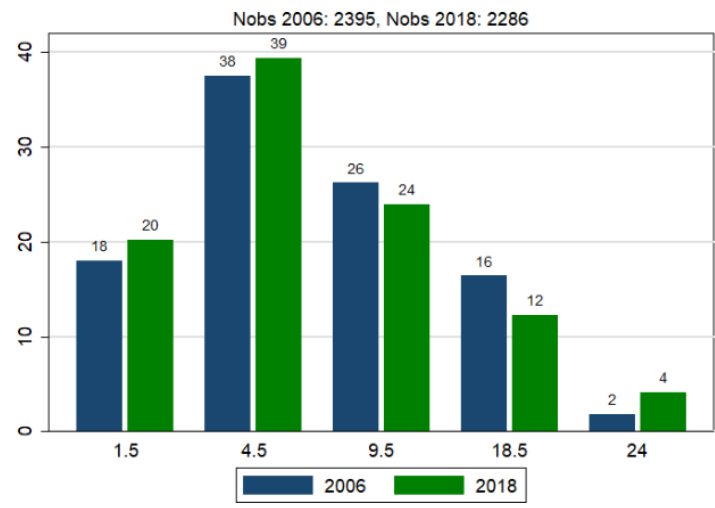

Communities Answering the Question in Both Surveys
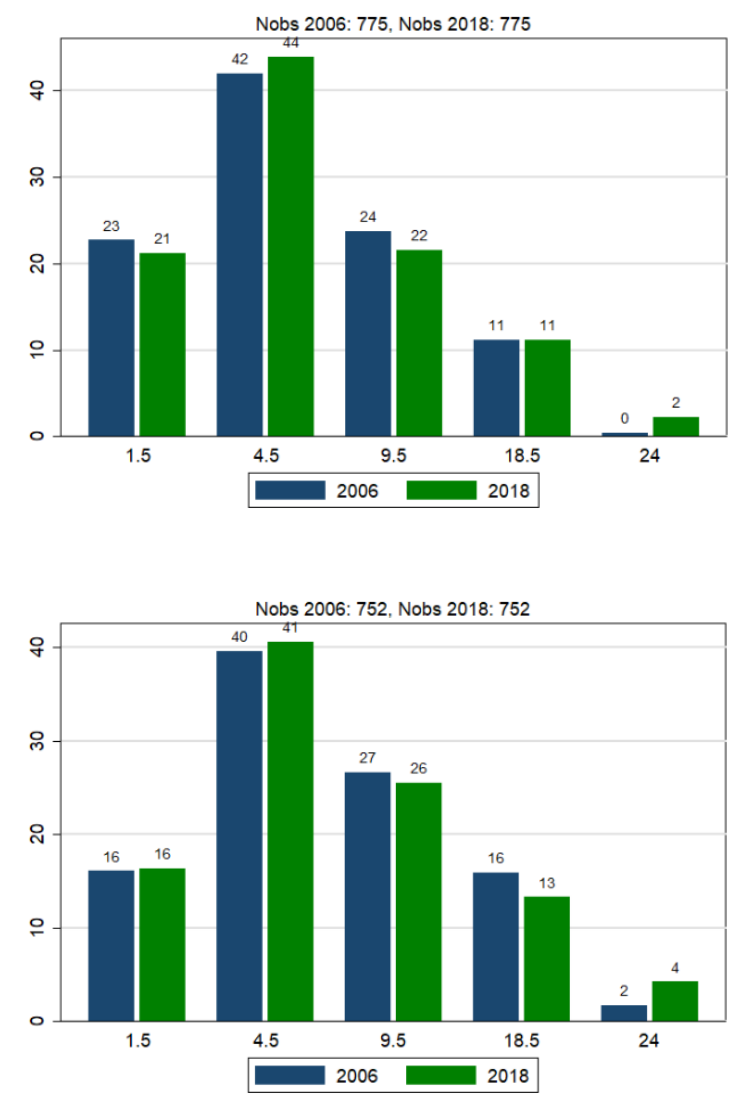

Share Decreasing $(-1)$,

Staying the Same (0), Increasing (1)
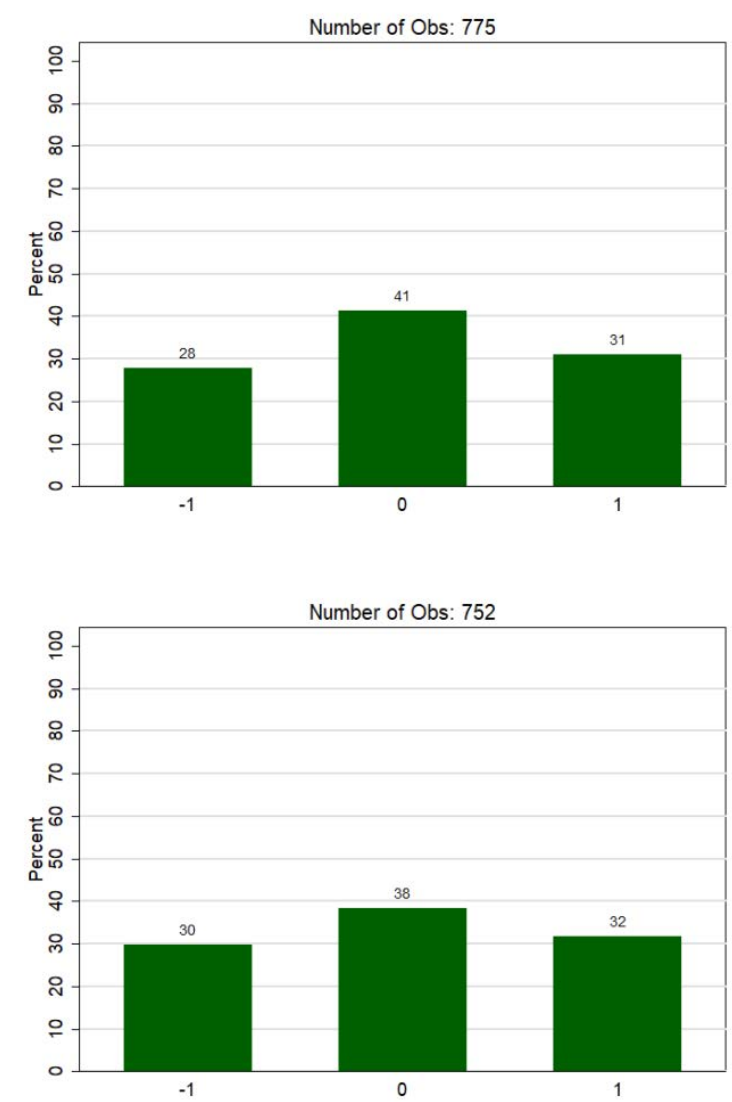


\section{Figure 2 (cont'd.)}

\section{All Communities Answering a Survey}

Multi Family, Rezoning

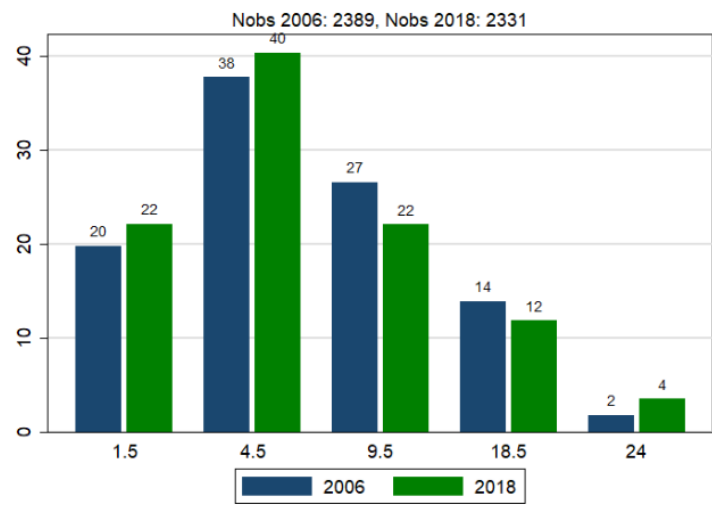

Single Family less than 50 Units, Subdivision

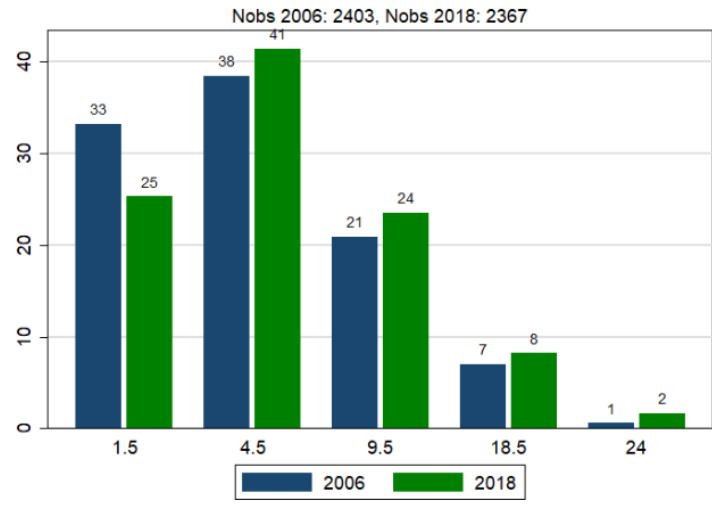

Communities Answering the Question in Both Surveys
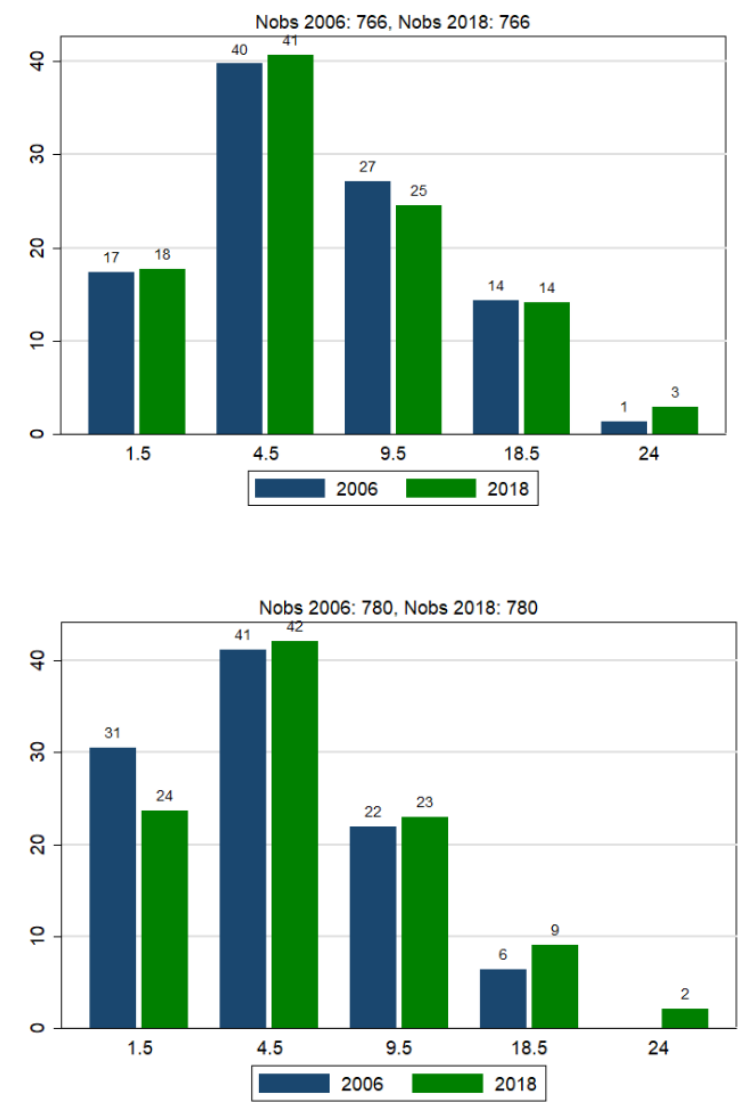

Share Decreasing (-1),

Staying the Same (0), Increasing (1)
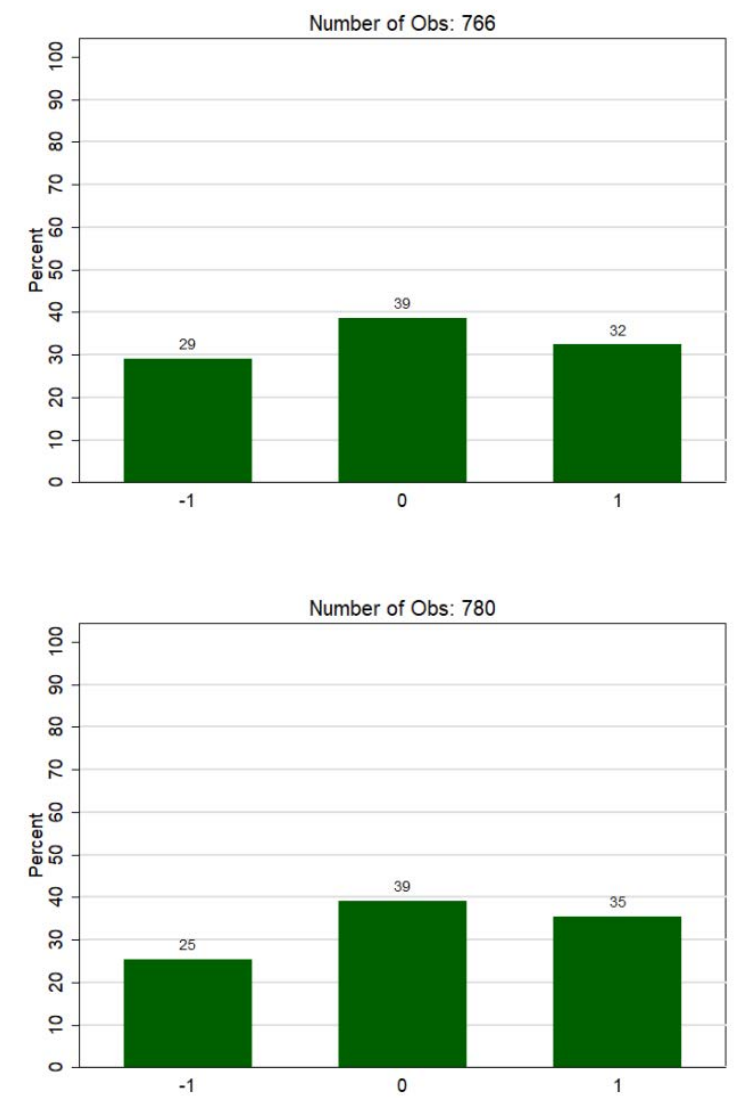


\section{Figure 2 (cont'd.)}

\section{All Communities Answering a Survey}

Single Family greater than 50 Units, Subdivision

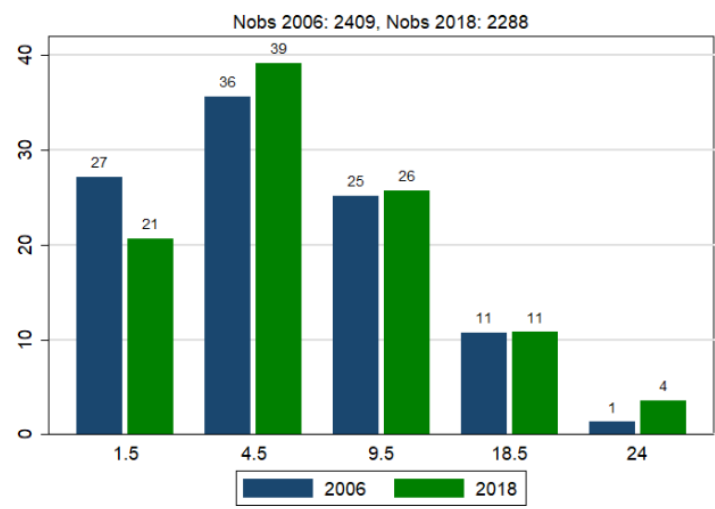

Multi Family, Subdivision

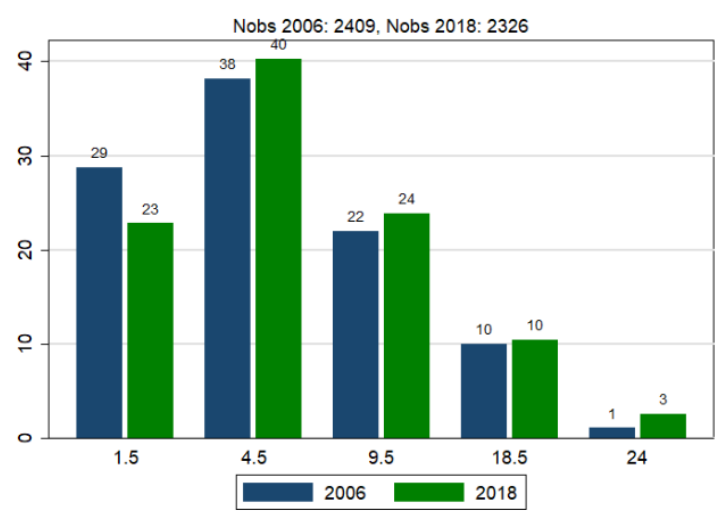

Communities Answering the Question in Both Surveys
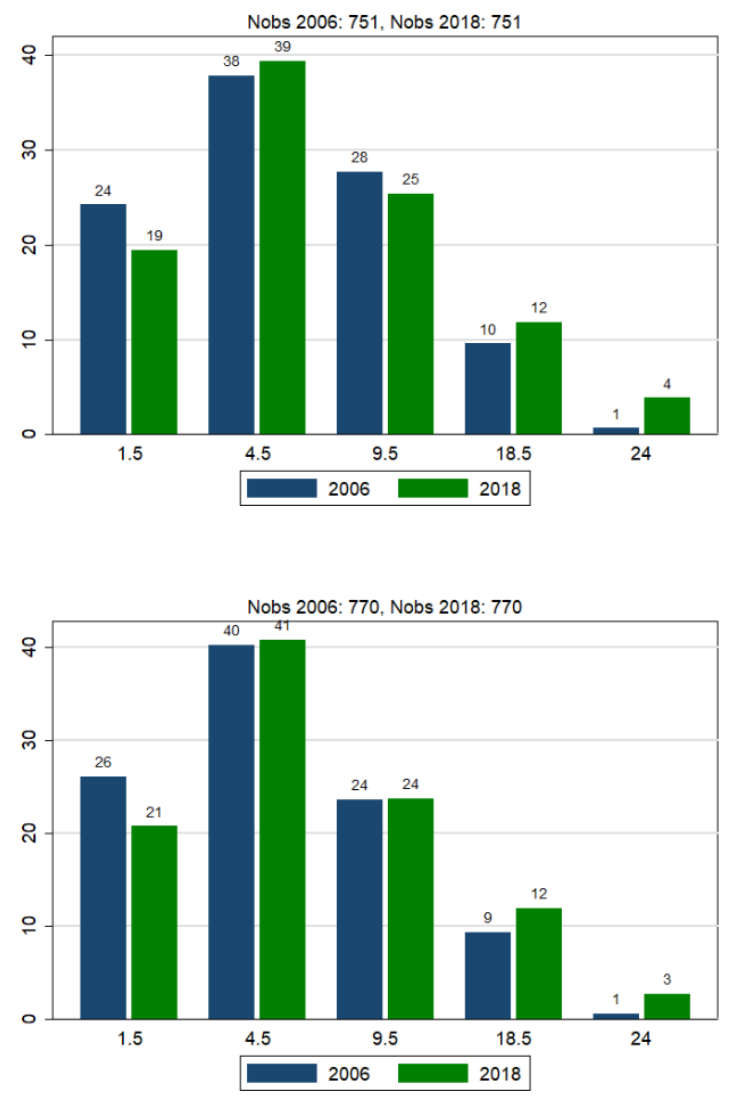

Share Decreasing (-1),

Staying the Same (0), Increasing (1)
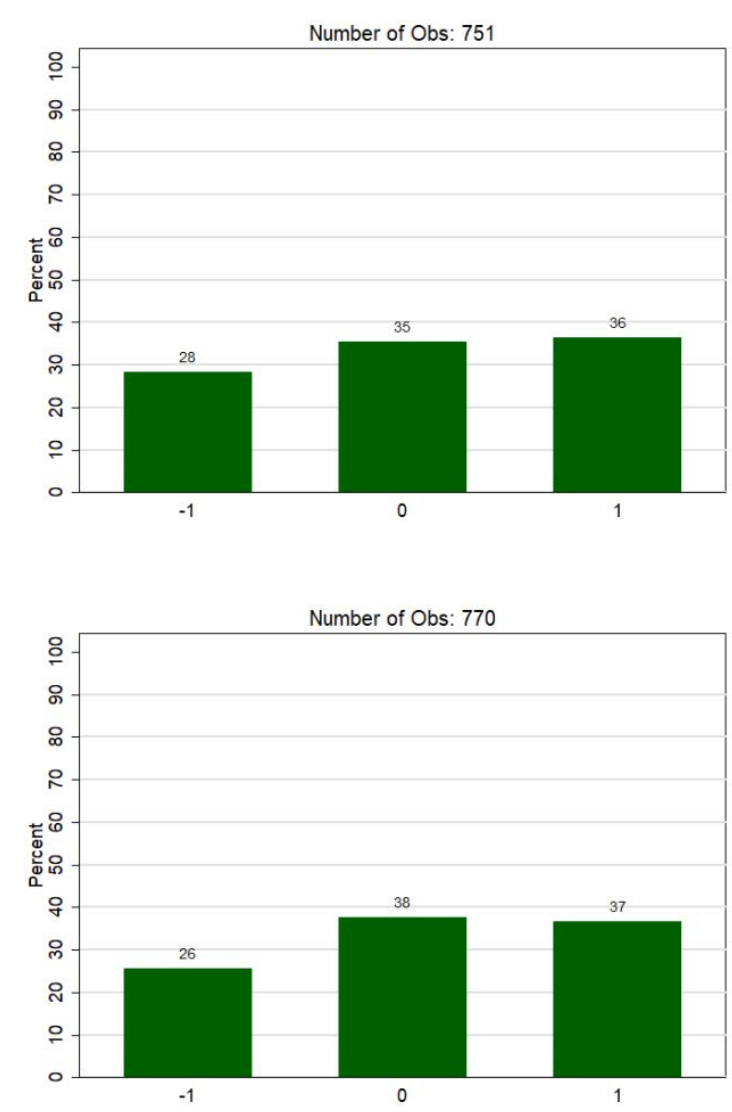
Figure 2 (cont'd.)

Net Change across Six Review Time Questions

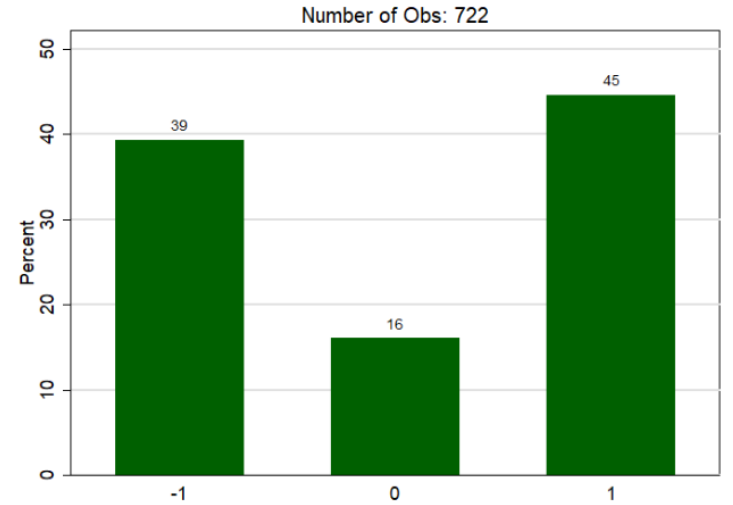


Figure 3: Changes in Political or Legal Involvement, 2006-2018

All Communities Answering a Survey

Communities Answering the Question in Both Surveys

Political Entity 1 - Local Council, Managers, or Commissioners

1 = Not Involved, 5 = Very Involved
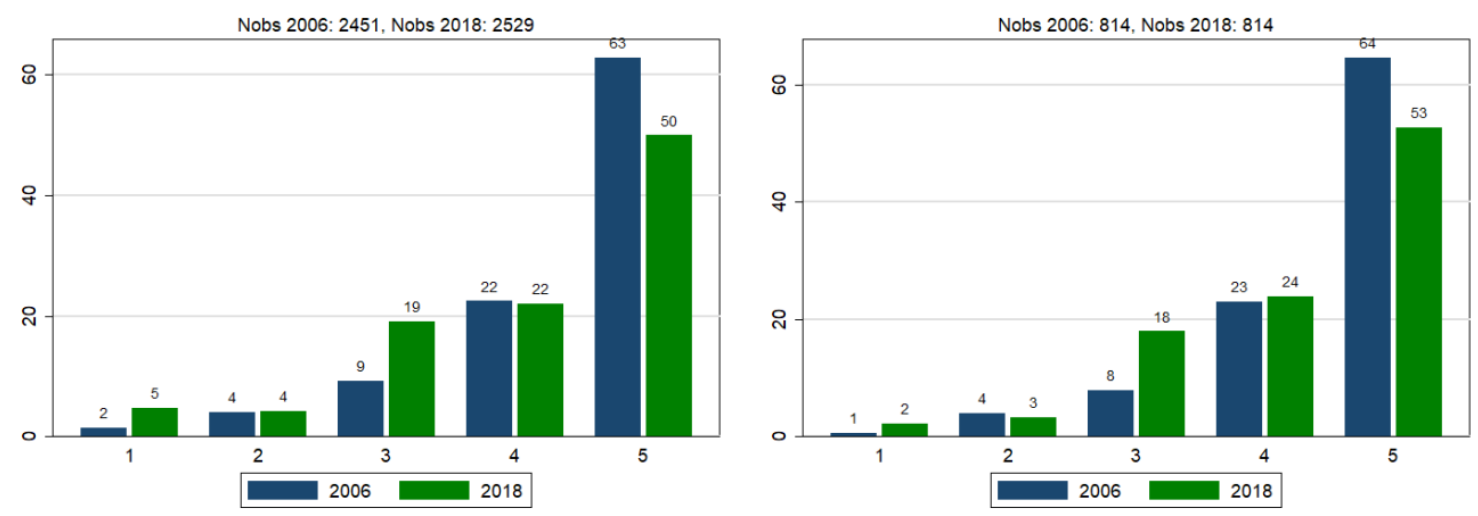

Political Entity 2 - Community Pressure

$1=$ Not Involved, 5 = Very Involved

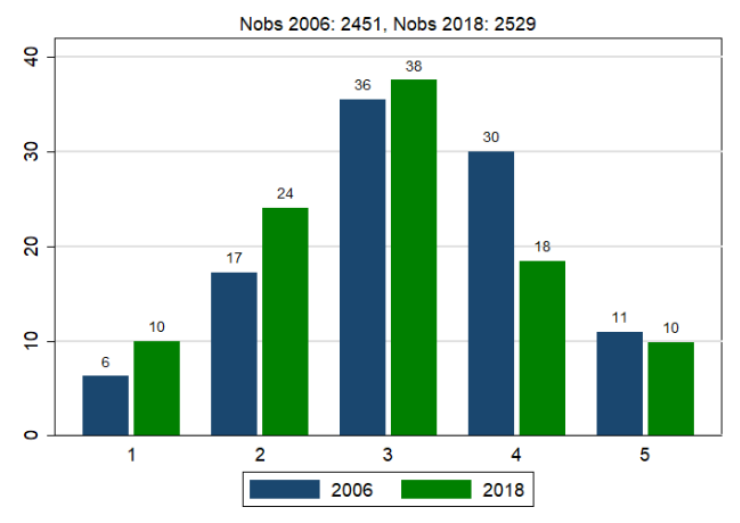

Nobs 2006: 814, Nobs 2018: 814

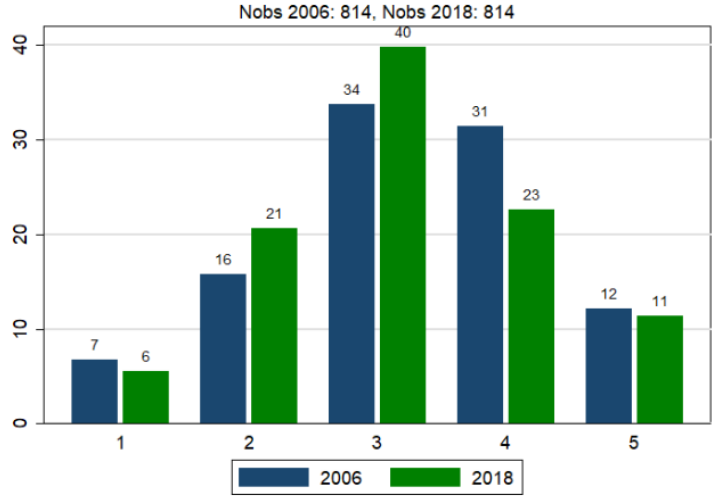

Share Decreasing (-1),

Staying the Same (0), Increasing (1)

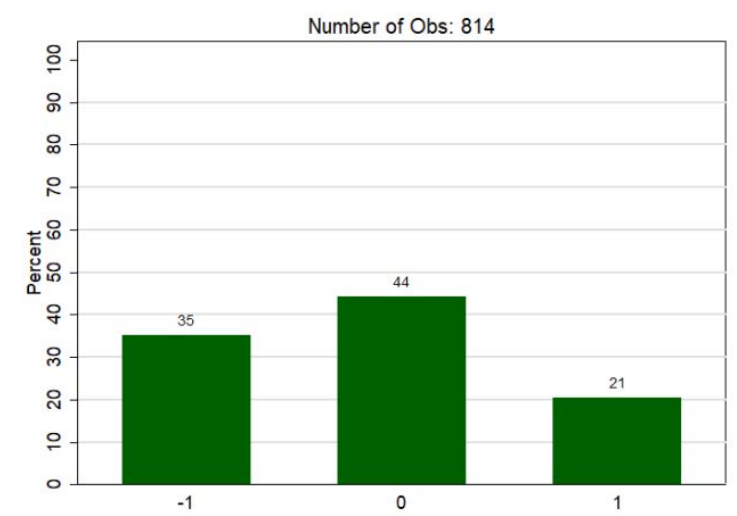

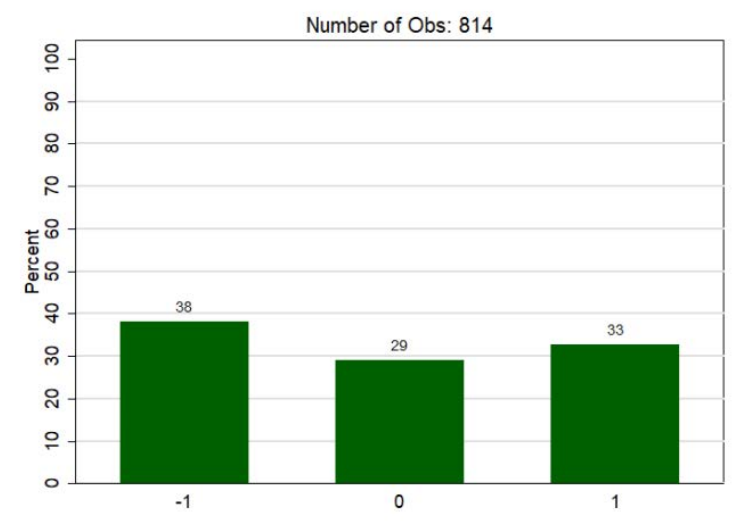


Figure 3: Changes in Political or Legal Involvement, 2006-2018 (cont’d.)

All Communities Answering a Survey

Political Entity 3 - State Legislature

1 = Not Involved, 5 = Very Involved

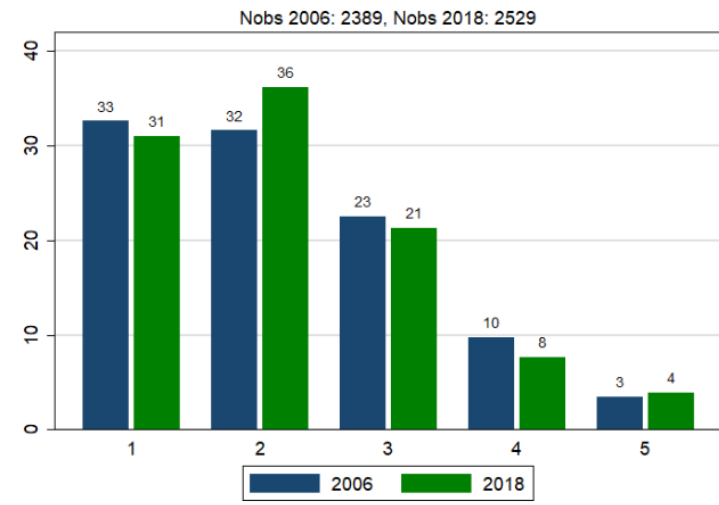

Political Entity 4 - Local Courts

1 = Not Involved, 5 = Very Involved

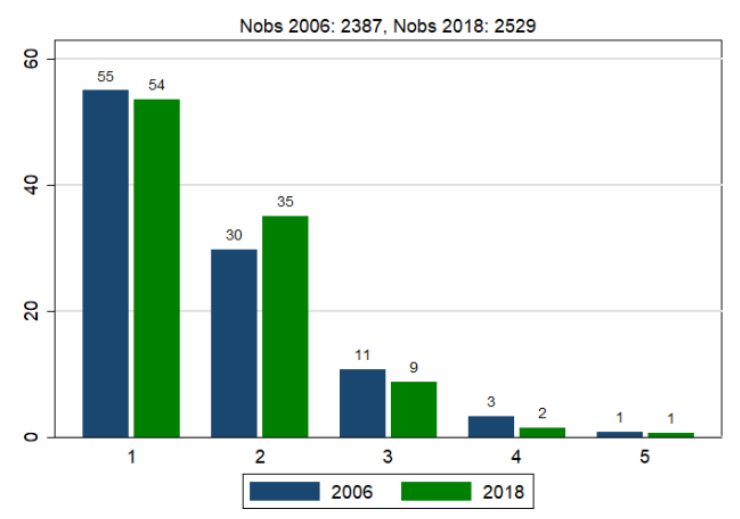

Communities Answering the Question in Both Surveys
Share Decreasing $(-1)$,

Staying the Same (0), Increasing (1)

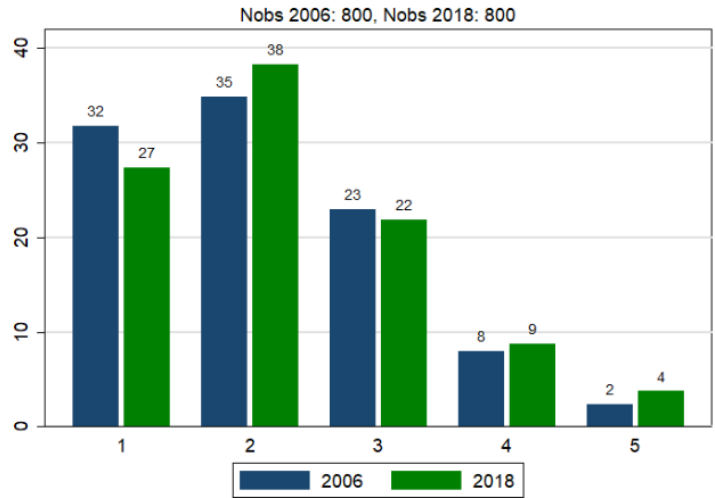

Nobs 2006: 799, Nobs 2018: 799

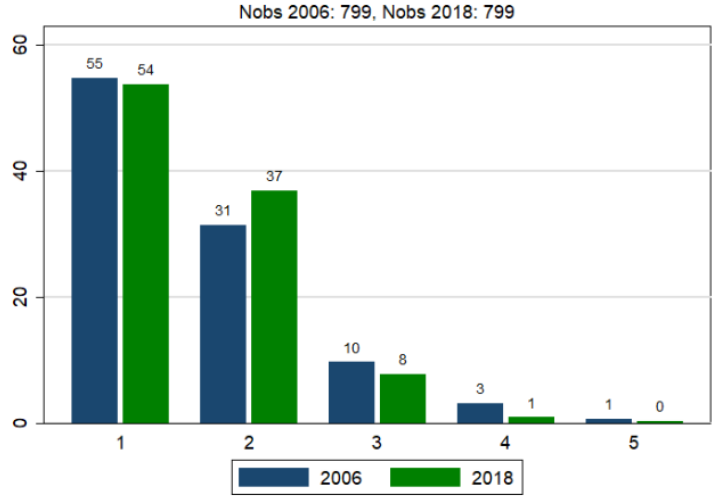

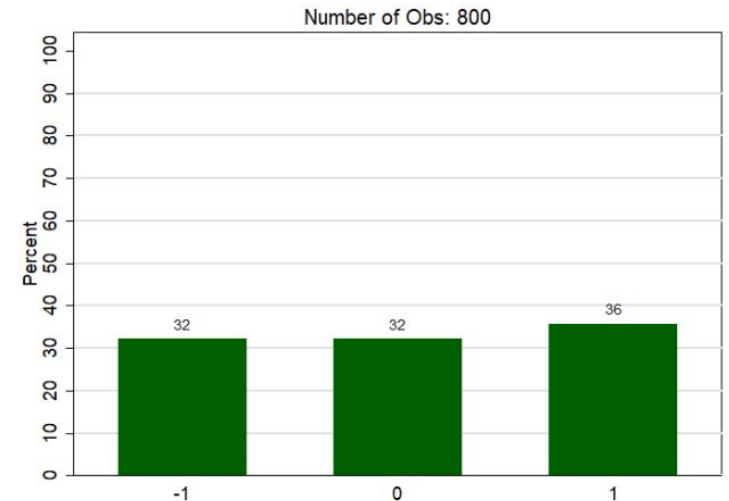

Number of Obs: 799

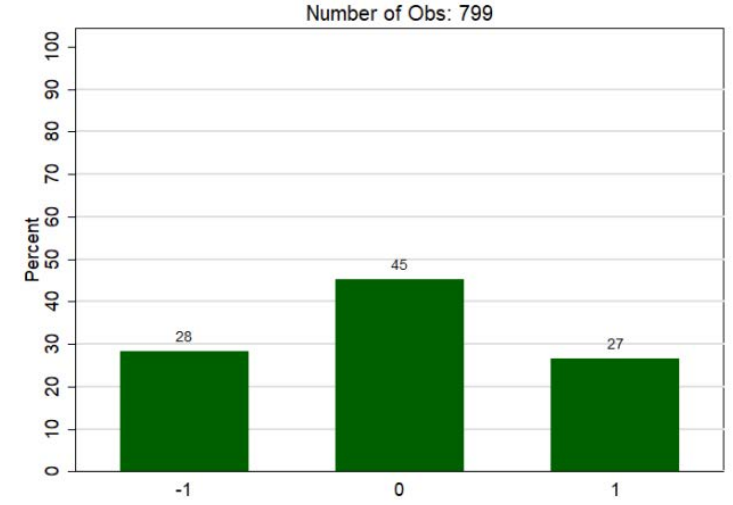


Figure 3: Changes in Political or Legal Involvement, 2006-2018 (cont'd.)

All Communities Answering a Survey

Political Entity 5 - State Courts

$1=$ Not Involved, 5 = Very Involved

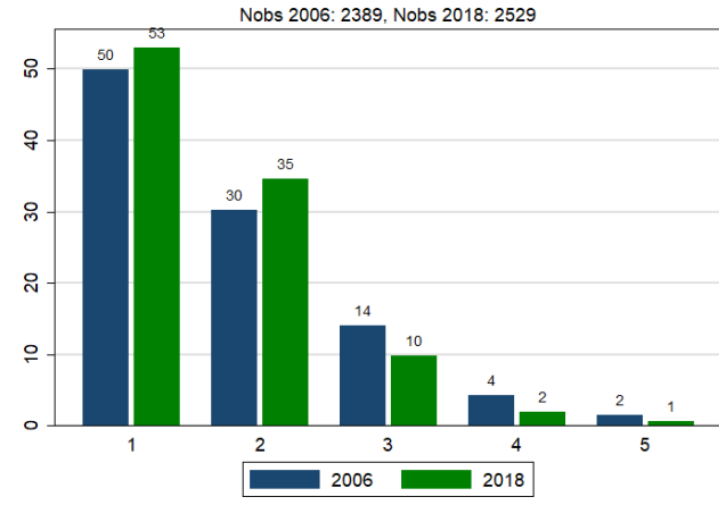

Communities Answering the Question in Both Surveys
Share Decreasing (-1),

Staying the Same (0), Increasing (1)
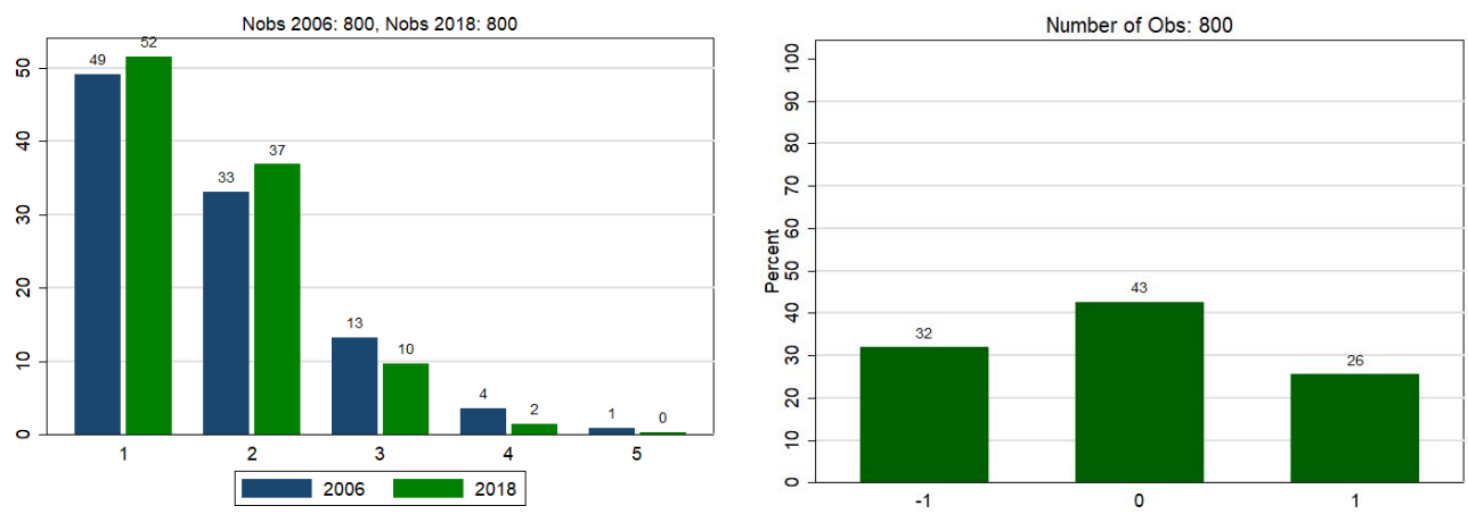
Figure 4: Aggregate Change in Regulation Strictness and in the Underlying Political/Legal Environment

Regulation Change Index

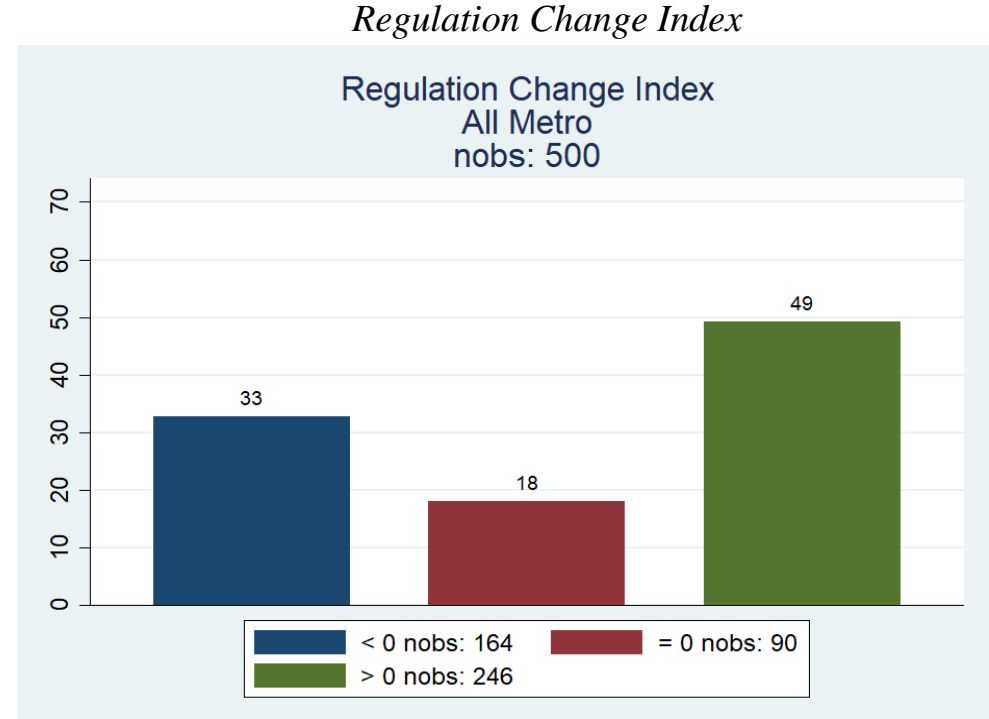

Political / Legal Change Index

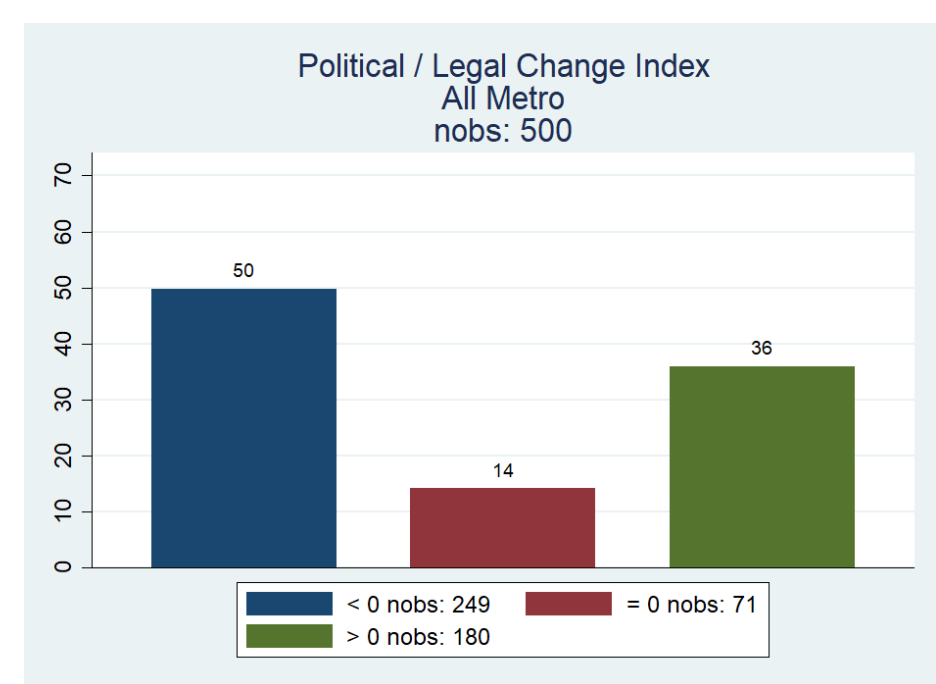




\section{Figure 5: Where Are the Communities that Increased or Decreased Their Degree of Regulation?}

CBSAs With at Least One Community Whose Regulation Change Index Rose

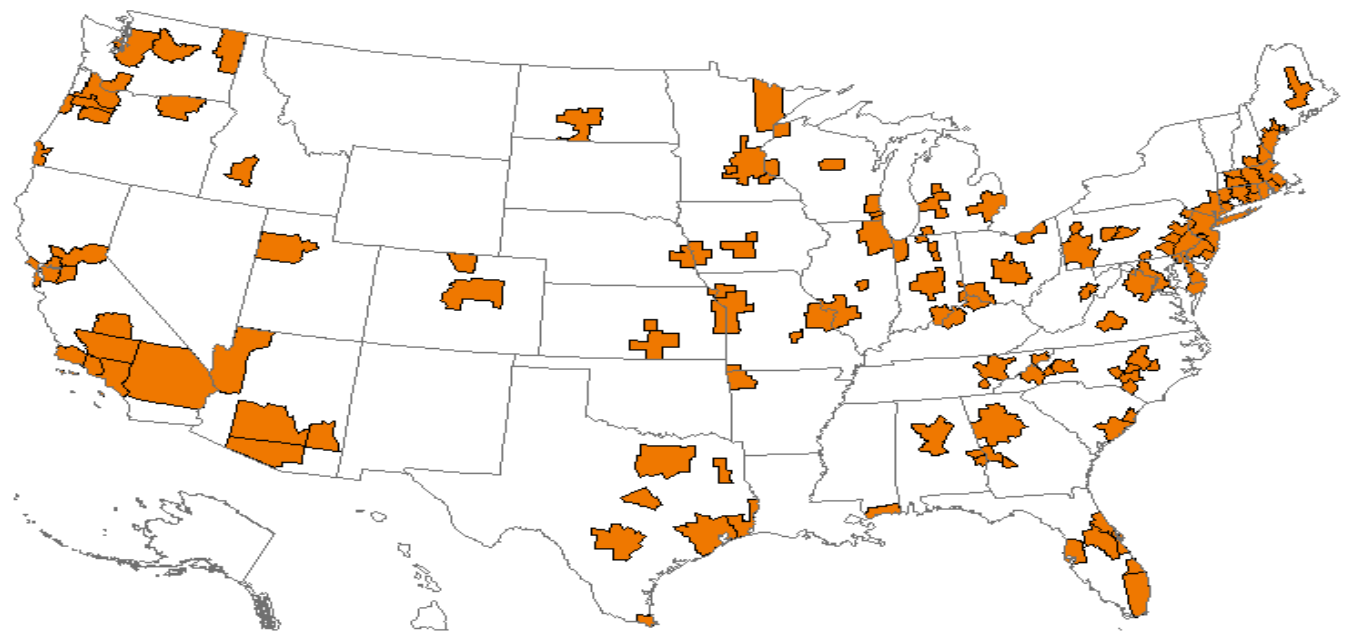

CBSAs With at Least One Community Whose Regulation Change Index Declined

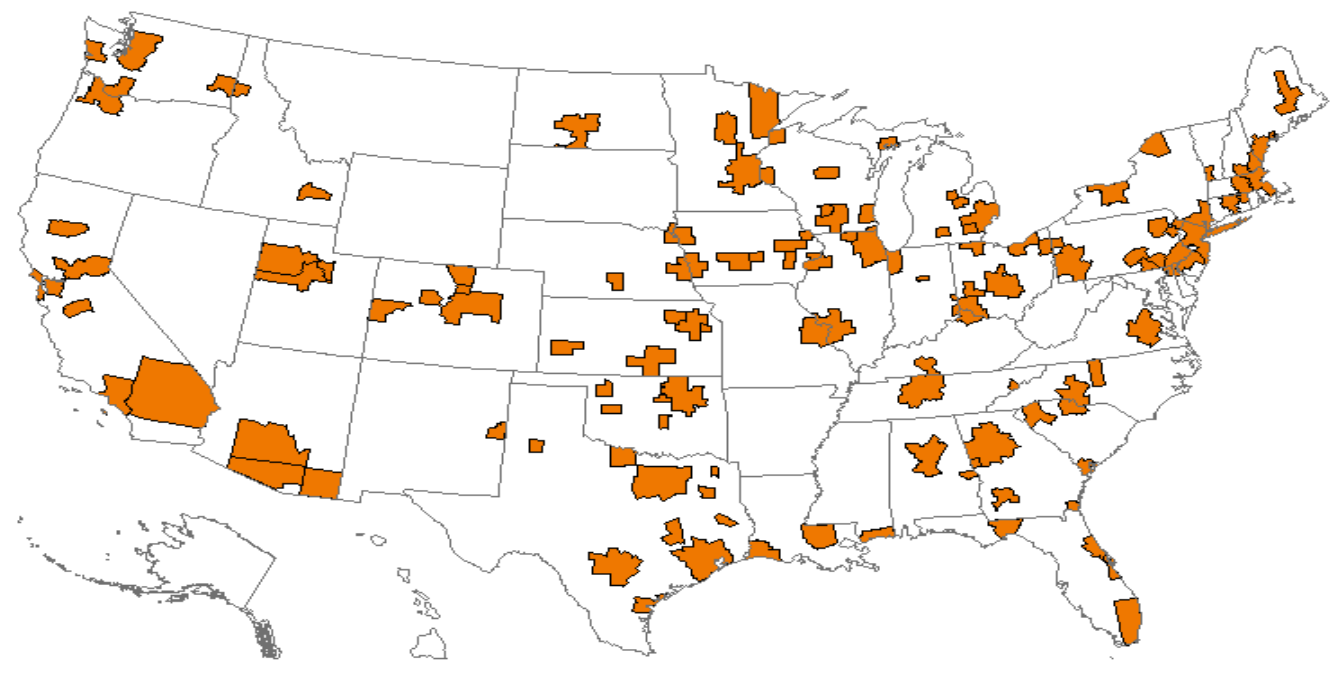


Table 1: WRLURI2018 and Its Components

(Full Sample: nobs=2,472)

\begin{tabular}{lcc}
\hline \hline & & \\
& Factor Loadings & \\
\cline { 2 - 3 } CII & 0.42 & 0.62 \\
SPII & 0.41 & 0.59 \\
LPPI & 0.40 & 0.58 \\
EI & 0.28 & 0.41 \\
ADI & 0.28 & 0.41 \\
LPAI & 0.29 & 0.42 \\
LZAI & 0.27 & 0.39 \\
OSI & 0.24 & 0.35 \\
AHI & 0.27 & 0.39 \\
LAI & 0.17 & 0.24 \\
SRI & 0.12 & 0.17 \\
DRI & 0.09 & 0.14
\end{tabular}


Table 2: WRLURI2018 Summary Statistics for Communities Inside and Outside CBSAs

\begin{tabular}{lccc}
\hline \hline & Full Sample & Metro Area & Non-Metro Area Sample \\
Mean & 0.00 & 0.03 & -0.30 \\
Standard Deviation & 1.00 & 0.98 & 1.15 \\
Minimum & -2.64 & -2.64 & -2.55 \\
1st percentile & -2.04 & -1.94 & -2.26 \\
10th percentile & -1.21 & -1.17 & -1.60 \\
25th percentile & -0.68 & -0.64 & -1.09 \\
50th percentile & -0.08 & -0.03 & -0.51 \\
75th percentile & 0.62 & 0.64 & 0.32 \\
90th percentile & 1.31 & 1.33 & 1.23 \\
99th percentile & 2.67 & 2.58 & 2.75 \\
Maximum & 4.86 & 3.94 & 4.86 \\
& & & 41,801 \\
Local Traits & & & 122,236 \\
Median Family Income (2010) & 62,259 & 64,429 & $18.87 \%$ \\
Median House Value (2010) & 217,140 & 227,206 & $18.64 \%$ \\
Percent College Graduates (2010) & $30.64 \%$ & $31.89 \%$ & $80.08 \%$ \\
Percent Poverty (2010) & $13.04 \%$ & $12.45 \%$ & 4,748 \\
Percentage White (2010) & $77.79 \%$ & $77.55 \%$ & 18.74 \\
Population (2010) & 23,909 & 25,950 & 883 \\
Land Area in Square Miles (2010) & 20.76 & 20.98 & 239 \\
Population Density Per Square Mile (2010) & 1,792 & 1,890 & 2,233 \\
\hline \hline Nobs & 2,472 & & \\
\hline \hline
\end{tabular}


Table 3: Variation Across the WRLURI2018 Distribution

(CBSA Sample; $n=2,233$ )

\begin{tabular}{|c|c|c|c|}
\hline & $\begin{array}{c}\text { Lightly-Regulated: } \\
\text { Bottom Quartile } \\
\text { WRLURI } 2018 \leq-0.64\end{array}$ & $\begin{array}{c}\text { Average Regulation: } \\
\text { Interquartile Range } \\
-0.642<\text { WRLURI } 2018< \\
0.637\end{array}$ & $\begin{array}{l}\text { Highly-Regulated: } \\
\quad \text { Top Quartile } \\
\text { WRLURI } 2018 \geq 0.64\end{array}$ \\
\hline \multicolumn{4}{|l|}{ Subindex } \\
\hline Local Political Pressure Index(LPPI) & 6.85 & 8.61 & 9.83 \\
\hline State Political Involvement Index(SPII) & 1.44 & 2.17 & 3.05 \\
\hline Court Involvement Index(CII) & 2.30 & 3.11 & 4.48 \\
\hline Local Assembly Index(LAI) & 0.33 & 0.44 & 0.60 \\
\hline Local Project Approval Index(LPAI) & 1.67 & 2.24 & 3.22 \\
\hline Local Zoning Approval Index(LZAI) & 2.28 & 2.79 & 3.69 \\
\hline Density Restriction Index(DRI) & 1.92 & 2.13 & 2.48 \\
\hline Supply Restrictions Index(SRI) & 0.04 & 0.11 & 0.36 \\
\hline Open Space Index(OSI) & 0.32 & 0.64 & 0.76 \\
\hline Exactions Index(EI) & 0.20 & 0.56 & 0.75 \\
\hline Affordable House Index(AHI) & 0.02 & 0.10 & 0.36 \\
\hline Approval Delay Index(ADI--months) & 3.7 & 5.0 & 8.4 \\
\hline \multicolumn{4}{|l|}{ Local Traits } \\
\hline Median Family Income (2010) & 55,817 & 63,790 & 74,235 \\
\hline Median House Value (2010) & 172,576 & 215,782 & 304,262 \\
\hline Percent College Graduates (2010) & $27.76 \%$ & $31.78 \%$ & $36.18 \%$ \\
\hline Percent Poverty (2010) & $14.55 \%$ & $12.23 \%$ & $10.80 \%$ \\
\hline Percentage White (2010) & $80.67 \%$ & $77.24 \%$ & $75.07 \%$ \\
\hline Population (2010) & 19,622 & 21,885 & 40,335 \\
\hline Land Area in Square Miles (2010) & 21.43 & 18.77 & 24.96 \\
\hline Population Density Per Square Mile (2010) & 1,671 & 1,883 & 2,118 \\
\hline Nobs & 559 & 1,116 & 558 \\
\hline
\end{tabular}




\begin{tabular}{|c|c|c|}
\hline $\begin{array}{l}\text { Lightly Regulated } \\
\text { WRLURI } 2018 \leq-0.64\end{array}$ & $\begin{array}{l}\text { Moderately Regulated } \\
-0.642<\text { WRLURI } 2018<0.637\end{array}$ & $\begin{array}{l}\text { Highly Regulated } \\
\text { WRLURI } 2018 \geq 0.64\end{array}$ \\
\hline $\begin{array}{l}\text { LPPI=6.85 } \\
\text { Moderate levels of involvement by } \\
\text { local political officials is common } \\
\text { among this group of places; the } \\
\text { modal response is for moderate } \\
\text { involvement ( } 34 \% \text { ); but } 47 \% \text { report } \\
\text { higher than moderate involvement } \\
\text { Community pressure is not high, as a } \\
\text { modal } 37 \% \text { report somewhat less } \\
\text { than moderate pressure, with another } \\
21 \% \text { reporting no meaningful } \\
\text { pressure } \\
\text { No other significant local political } \\
\text { actor is involved; only } 6 \% \text { report any } \\
\text { such actor. }\end{array}$ & $\begin{array}{l}\text { LPPI=8.61 } \\
\text { High involvement of local political officials- } \\
\text { council, managers, commissioners; } 80 \% \text { of } \\
\text { these communities report greater than } \\
\text { moderate involvement } \\
\text { Moderate level of community pressure; } 43 \% \\
\text { report moderate involvement; only 27\% } \\
\text { report more than moderate involvement } \\
\text { No other significant local political actor is } \\
\text { involved in the regulatory process; only } 11 \% \\
\text { report another such actor and only } 2 \% \text { report } \\
\text { any type of ballot initiative }\end{array}$ & $\begin{array}{l}\text { LPPI=9.83 } \\
\text { High level of involvement by local public } \\
\text { officials-90\% report more than moderate levels of } \\
\text { involvement, with over two-thirds reporting very } \\
\text { high involvement } \\
\text { Moderate level of community pressure; 34\% report } \\
\text { average involvement on a 1-5 scale; but 55\% report } \\
\text { greater than average involvement } \\
\text { 1-in-5 highly regulated communities reports at } \\
\text { least one other important player in the local } \\
\text { regulatory process; this certainly is well under } \\
\text { half, so it is not typical; however, it is double the } \\
\text { level of the places in the interquartile range and 3+ } \\
\text { times the level reported by lightly-regulated places }\end{array}$ \\
\hline $\begin{array}{l}\text { SPII=1.44 } \\
\text { Nearly two-thirds (64\%) of } \\
\text { respondents report no meaningful } \\
\text { involvement in the regulatory } \\
\text { process by the state legislature; only } \\
6 \% \text { report moderate levels of } \\
\text { involvement (or higher) }\end{array}$ & $\begin{array}{l}\text { SPII }=2.17 \\
\text { State legislature is only modestly involved in } \\
\text { the regulatory process; almost one-quarter of } \\
\text { respondents claimed no meaningful } \\
\text { involvement at all }\end{array}$ & $\begin{array}{l}\text { SPII=3.05 } \\
\text { Moderate involvement of the state legislature is the } \\
\text { mode of this group of places }\end{array}$ \\
\hline $\begin{array}{l}\text { CII=2.30 } \\
86 \% \text { of respondents report no } \\
\text { effective involvement by either the } \\
\text { local or state court system. }\end{array}$ & $\begin{array}{l}\text { CII=3.11 } \\
\text { Neither state nor local courts are major } \\
\text { players in the regulatory process; just over } \\
\text { one-half of this group indicated no } \\
\text { meaningful role for the court system }\end{array}$ & $\begin{array}{l}\text { CII=4.48 } \\
\text { Court involvement in the regulatory process is } \\
\text { greater for this group, but it still is less than } \\
\text { moderate on average; } 70 \% \text { of respondents report } \\
\text { having less than moderate involvement for either } \\
\text { court system }\end{array}$ \\
\hline
\end{tabular}


Table 4 Continued

Lightly Regulated

WRLURI $2018 \leq-0.64$

\section{$\mathrm{LAI}=0.33$}

Only one-third of this group reported a town meeting option.

\section{LPAI $=1.67$}

The modal response (at 32\%) reports two entities are required to approve a project that does not require any zoning changes; 58\% note a local planning commission must be involved; the next highest share, at $42 \%$, is for a local council.

\section{$\mathrm{LZAI}=2.28$}

The mode here is also for two entities (43\%); 73\% of respondents note that local planning commission approval is required; $69 \%$ note the same for a local council, with 51\% claiming local zoning board approval is required; no other entity listed has more than a $6 \%$ share

\section{DRI $=1.92$}

Density restrictions are wide spread even among the most lightlyregulated communities in the U.S.; $94 \%$ of this group reports having some type of minimum lot size requirement; the most common size is for less than one-half acre per lot
Moderately Regulated

$-0.642<$ WRLURI $2018<0.637$

\section{$\mathrm{LAI}=0.44$}

The typical town in this group does not have some type of open meeting requirement; that said, the actual share who does is $45 \%$, so it is not uncommon

\section{$\mathrm{LPAI}=2.24$}

At least two distinct entities are required to approve projects that do not require any change in zoning - i.e., they are "by right"; (60\% of respondents indicated a local planning commission was required to approve projects; $59 \%$ said a local council or commission was required; the next largest response rate was for the local zoning board at $33 \%$, with $12 \%$ naming a design review board).

\section{LZAI $=2.79$}

For projects needing rezoning, 84\% said the local planning commission had to give approval; 81\% stated the local council had to do so; $53 \%$ noted a local zoning board had approval rights. A design review board was the next most cited body at $11 \%$

\section{$\mathrm{DRI}=2.13$}

Density restrictions in the form of minimum lot sizes are omnipresent; 95\% of places have a minimum in at least one neighborhood; it typically is less than 0.5 acres for a lot, but $55 \%$ of the group have a minimum greater than one-half acre.
Highly Regulated

WRLURI $2018 \geq 0.64$

\section{$\mathrm{LAI}=0.60$}

Only in the most highly-regulated places does the typical community have a public (or town) meeting requirement (60\% do)

\section{LPAI $=3.22$}

At least three entities are required to approve a project that does not require rezoning among this highly-regulated group of places; local planning commissions and local councils are mentioned by well over half the respondents; $40 \%$ note that a local zoning board's approval is required, with all six other entities listed in the underlying question being mentioned by at least $10 \%$ of this group

\section{LZAI=3.69}

Nearly four entities are required to approve a project that requires rezoning; local planning commissions and local councils are involved in $80+\%$ of respondents; the analogous number for local zoning boards is 54\%; all six other entities are required in at least $10 \%$ of respondents, with design review boards being reported in over onequarter

\section{DRI $=2.48$}

All but $2 \%$ of these communities have some type of minimum lot size requirement; the modal community has at least one neighborhood with a $2+$ acre minimum 


\begin{tabular}{|c|c|c|}
\hline $\begin{array}{l}\text { Lightly Regulated } \\
\text { WRLURI } 2018 \leq-0.64\end{array}$ & $\begin{array}{l}\text { Moderately Regulated } \\
-0.642<\text { WRLURI } 2018<0.637\end{array}$ & $\begin{array}{l}\text { Highly Regulated } \\
\text { WRLURI } 2018 \geq 0.64\end{array}$ \\
\hline $\begin{array}{l}\text { SRI }=0.04 \\
\text { Virtually none of this group reported } \\
\text { any type of formal limit or cap on } \\
\text { permits or building of single-family } \\
\text { or multifamily housing }\end{array}$ & $\begin{array}{l}\text { SRI=0.11 } \\
\text { Formal limits or hard caps on permitting or } \\
\text { building of any type are rare; only 1-3\% of } \\
\text { this group has any such requirement }\end{array}$ & $\begin{array}{l}\text { SRI }=0.36 \\
\text { Formal limits on permitting or construction are rare } \\
\text { among this group, too; only 1-in-20 have any such } \\
\text { limit. }\end{array}$ \\
\hline $\begin{array}{l}\text { OSI }=0.32 \\
\text { The typical lightly-regulated } \\
\text { community does not have an open } \\
\text { space requirement ( } 32 \% \text { of this } \\
\text { group does) }\end{array}$ & $\begin{array}{l}\text { OSI }=0.64 \\
\text { Open space requirements are the norm for this } \\
\text { group of communities, with } 64 \% \text { reporting } \\
\text { them }\end{array}$ & $\begin{array}{l}\text { OSI }=0.76 \\
\text { Three-fourths of these communities have open } \\
\text { space requirements }\end{array}$ \\
\hline $\begin{array}{l}\text { EI=0.20 } \\
\text { Exaction fees are imposed in only } \\
20 \% \text { of this group of communities }\end{array}$ & $\begin{array}{l}\text { EI=0.56 } \\
\text { Exaction fees are more common than not, } \\
\text { with } 56 \% \text { of communities reporting them }\end{array}$ & $\begin{array}{l}\text { EI=0.75 } \\
\text { Three-fourths of these communities have exaction } \\
\text { fee programs }\end{array}$ \\
\hline $\begin{array}{l}\text { AHI }=0.02 \\
\text { Affordable housing requirements are } \\
\text { quite rare, as only } 1 \text {-in- } 50 \text { of the } \\
\text { more lightly-regulated places has } \\
\text { such a program }\end{array}$ & $\begin{array}{l}\text { AHI }=0.10 \\
\text { Affordable housing requirements are rare, } \\
\text { with only } 10 \% \text { of communities in this group } \\
\text { reporting them }\end{array}$ & $\begin{array}{l}\text { AHI }=0.36 \\
\text { Affordable housing programs are relatively rare } \\
\text { even among this group of highly regulated places; } \\
\text { still, over one-third have some such program }\end{array}$ \\
\hline $\begin{array}{l}\text { ADI }=3.7 \\
\text { This is a } 3.7 \text { month average delay } \\
\text { between project application and } \\
\text { receiving a decision from the } \\
\text { government }\end{array}$ & $\begin{array}{l}\text { ADI }=5 \\
\text { There is an average } 5 \text { month lag between } \\
\text { submitting a request for project approval and } \\
\text { hearing back with a decision }\end{array}$ & $\begin{array}{l}\text { ADI=8.4 } \\
\text { Review times are longer here, averaging } 8.4 \\
\text { months; there is a large } 6.9 \text { month standard } \\
\text { deviation, so the communities in the upper tail of } \\
\text { this distribution have } 18-24 \text { month delays }\end{array}$ \\
\hline
\end{tabular}


Table 5: WRLURI2018 Values for CBSAs with Ten or More Observations

\begin{tabular}{|c|c|c|c|c|c|}
\hline CBSA Name & WRLURI & \# Obs & CBSA Name & WRLURI & \# Obs \\
\hline 1. San Francisco-Oakland-Hayward, CA & 1.18 & 18 & 23. Dallas-Fort Worth-Arlington, TX & 0.17 & 49 \\
\hline 2. New York-Newark-Jersey City, NY-NJ-PA & 1.04 & 57 & 24. Hartford-West Hartford-East Hartford, CT & 0.14 & 14 \\
\hline 3. Providence-Warwick, RI-MA & 0.93 & 14 & 25. Portland-South Portland, ME & 0.13 & 16 \\
\hline 4. Seattle-Tacoma-Bellevue, WA & 0.73 & 22 & 26. Kansas City, MO-KS & 0.13 & 17 \\
\hline 5. Los Angeles-Long Beach-Anaheim, CA & 0.73 & 48 & 27. San Antonio-New Braunfels, TX & 0.10 & 10 \\
\hline 6. Riverside-San Bernardino-Ontario, CA & 0.68 & 18 & 28. Buffalo-Cheektowaga-Niagara Falls, NY & 0.05 & 12 \\
\hline 7. Washington-Arlington-Alexandria, DC-VA-MD-WV & 0.66 & 16 & 29. Harrisburg-Carlisle, PA & 0.01 & 15 \\
\hline 8. Miami-Fort Lauderdale-West Palm Beach, FL & 0.66 & 35 & 30. Lancaster, PA & -0.01 & 14 \\
\hline 9. Phoenix-Mesa-Scottsdale, AZ & 0.64 & 11 & 31. Columbus, $\mathrm{OH}$ & -0.01 & 17 \\
\hline 10. Portland-Vancouver-Hillsboro, OR-WA & 0.60 & 18 & 32. Houston-The Woodlands-Sugar Land, TX & -0.04 & 16 \\
\hline 11. Madison, WI & 0.60 & 13 & 33. Pittsburgh, PA & -0.06 & 56 \\
\hline 12. Philadelphia-Camden-Wilmington, PA-NJ-DE-MD & 0.48 & 49 & 34. Minneapolis-St. Paul-Bloomington, MN-WI & -0.10 & 48 \\
\hline 13. Albany-Schenectady-Troy, NY & 0.47 & 10 & 35. Chicago-Naperville-Elgin, IL-IN-WI & -0.10 & 94 \\
\hline 14. Denver-Aurora-Lakewood, CO & 0.41 & 16 & 36. Atlanta-Sandy Springs-Roswell, GA & -0.12 & 27 \\
\hline 15. Youngstown-Warren-Boardman, OH-PA & 0.32 & 10 & 37. Worcester, MA-CT & -0.23 & 16 \\
\hline 16. Boston-Cambridge-Newton, MA-NH & 0.30 & 44 & 38. Cleveland-Elyria, $\mathrm{OH}$ & -0.28 & 19 \\
\hline 17. Indianapolis-Carmel-Anderson, IN & 0.30 & 14 & 39. Grand Rapids-Wyoming, MI & -0.31 & 24 \\
\hline 18. Scranton--Wilkes-Barre--Hazleton, PA & 0.30 & 10 & 40. Rochester, NY & -0.38 & 26 \\
\hline 19. Syracuse, NY & 0.25 & 11 & 41. Charlotte-Concord-Gastonia, NC-SC & -0.38 & 12 \\
\hline 20. Milwaukee-Waukesha-West Allis, WI & 0.24 & 22 & 42. Cincinnati, OH-KY-IN & -0.38 & 26 \\
\hline 21. Allentown-Bethlehem-Easton, PA-NJ & 0.22 & 14 & 43. Detroit-Warren-Dearborn, MI & -0.42 & 60 \\
\hline 22. Nashville-Davidson--Murfreesboro--Franklin, TN & 0.17 & 12 & 44. St. Louis, MO-IL & -0.51 & 37 \\
\hline
\end{tabular}


Table 6: Share of Places in Top WRLURI18 Quartile for CBSAs with Ten or More Observations

\begin{tabular}{lllc}
\hline \hline CBSA Name & $\begin{array}{l}\text { Share in Top } \\
\text { WRLURI Quartile }\end{array}$ & CBSA Name & $\begin{array}{c}\text { Share in Top } \\
\text { WRLURI Quartile }\end{array}$ \\
\hline 1. San Francisco & 0.78 & 23. Dallas & 0.31 \\
2. New York & 0.65 & 24. Hartford & 0.29 \\
3. Providence & 0.57 & 25. Portland & 0.31 \\
4. Seattle & 0.59 & 26. Kansas City & 0.35 \\
5. Los Angeles & 0.46 & 27. San Antonio & 0.20 \\
6. Riverside & 0.56 & 28. Buffalo & 0.25 \\
7. Washington DC & 0.44 & 29. Harrisburg & 0.27 \\
8. Miami & 0.51 & 30. Lancaster & 0.21 \\
9. Phoenix & 0.55 & 31. Columbus & 0.24 \\
10. Portland & 0.50 & 32. Houston & 0.25 \\
11. Madison & 0.46 & 33. Pittsburgh & 0.18 \\
12. Philadelphia & 0.41 & 34. Minneapolis & 0.15 \\
13. Albany & 0.30 & 35. Chicago & 0.17 \\
14. Denver & 0.44 & 36. Atlanta & 0.07 \\
15. Youngstown & 0.30 & 37. Worcester & 0.19 \\
16. Boston & 0.39 & 38. Cleveland & 0.16 \\
17. Indianapolis & 0.14 & 39. Grand Rapids & 0.08 \\
18. Scranton & 0.40 & 40. Rochester & 0.15 \\
19. Syracuse & 0.36 & 41. Charlotte & 0.08 \\
20. Milwaukee & 0.23 & 42. Cincinnati & 0.08 \\
21. Allentown & 0.36 & 43. Detroit & 0.13 \\
22. Nashville & 0.33 & 44. St. Louis & 0.08 \\
& & & \\
\hline \hline Note: There are 1,107 communities within these 44 CBSAs. & & \\
\hline \hline & & & \\
\hline
\end{tabular}


Table 7: Regulatory Change Index Net Change-Community Share, by Region

\begin{tabular}{lccc}
\hline \hline & $\begin{array}{c}\text { Increasing Regulation } \\
\text { Over Time } \\
\text { (Net Change }>=+1)\end{array}$ & $\begin{array}{c}\text { No Change } \\
\text { Over Time } \\
\text { (Net Change = ) }\end{array}$ & $\begin{array}{c}\text { Decreasing Regulation } \\
\text { Over Time } \\
\text { (Net Change <= -1) }\end{array}$ \\
\hline 1. West Coast & $63 \%$ & $22 \%$ & $15 \%$ \\
2. West Coast, Not Coastal & $61 \%$ & $11 \%$ & $28 \%$ \\
3. East Coast & $59 \%$ & $21 \%$ & $21 \%$ \\
4. Northeast, Not Coastal & $53 \%$ & $14 \%$ & $34 \%$ \\
5. Sunbelt & $52 \%$ & $15 \%$ & $33 \%$ \\
6. Midwest & $41 \%$ & $21 \%$ & $38 \%$ \\
7. Rustbelt & $39 \%$ & $23 \%$ & $38 \%$ \\
8. Mountain & $33 \%$ & $21 \%$ & $46 \%$ \\
\hline
\end{tabular}

Notes: The number of community-level observations in each regional grouping are as follows: West Coast (46), West Coast-Not Coastal (18), East Coast (29), Northeast-Not Coastal (80), Sunbelt (142), Midwest (95), Rustbelt (66), and Mountain (24).

Table 8: Political/Legal Index Net Change-Community Share, By Region

\begin{tabular}{lccc}
\hline \hline & $\begin{array}{c}\text { Increasing Political/Legal } \\
\text { Involvement Over Time } \\
\text { (Net Change > +1) }\end{array}$ & $\begin{array}{c}\text { No Change Over } \\
\text { Time } \\
\text { (Net Change =) }\end{array}$ & $\begin{array}{c}\text { Decreasing Political/Legal } \\
\text { Involvement Over Time } \\
\text { (Net Change <=-1) }\end{array}$ \\
\hline 1. West Coast & $41 \%$ & $17 \%$ & $41 \%$ \\
2. West Coast-Not Coastal & $50 \%$ & $6 \%$ & $44 \%$ \\
3. East Coast & $28 \%$ & $21 \%$ & $52 \%$ \\
4. Northeast-Not Coastal & $40 \%$ & $11 \%$ & $49 \%$ \\
5. Sunbelt & $38 \%$ & $13 \%$ & $49 \%$ \\
6. Midwest & $29 \%$ & $17 \%$ & $54 \%$ \\
7. Rustbelt & $30 \%$ & $12 \%$ & $58 \%$ \\
8. Mountain & $42 \%$ & $17 \%$ & $42 \%$ \\
\hline
\end{tabular}

Notes: The number of community-level observations in each regional grouping are as follows: West Coast (46), West Coast-Not Coastal (18), East Coast (29), Northeast-Not Coastal (80), Sunbelt (142), Midwest (95), Rustbelt (66), and Mountain (24). 